GB2401

C $6 \mathrm{q}$

no. $79-29$

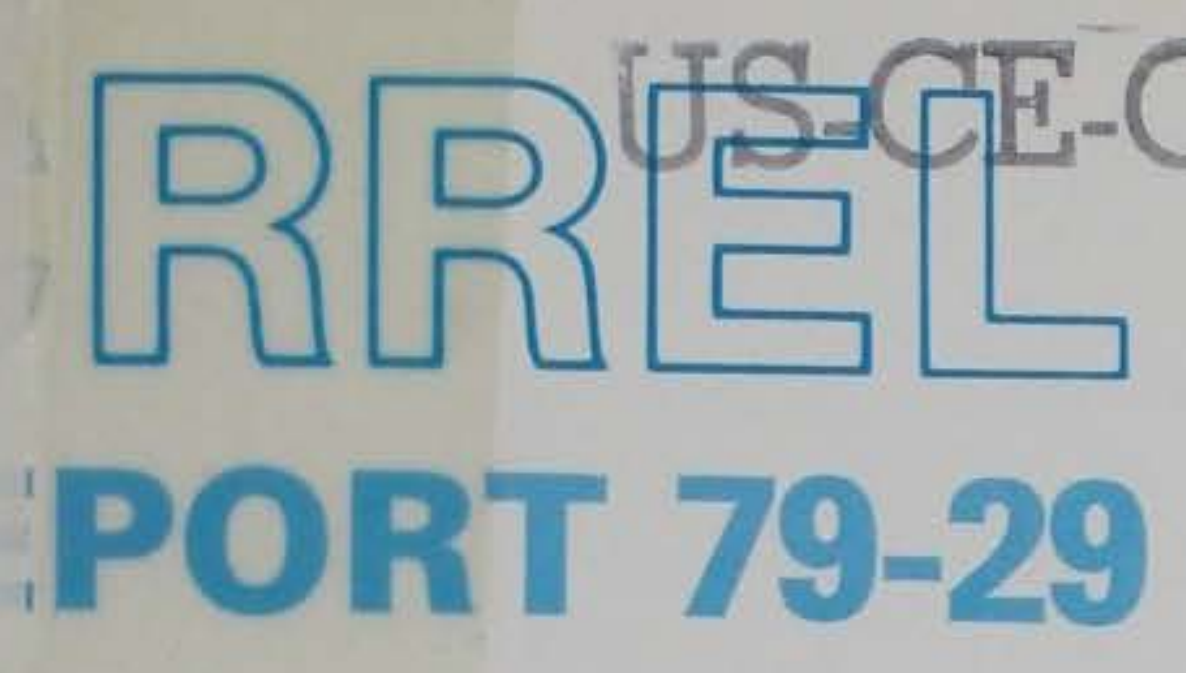

Property of the United States Govermmen

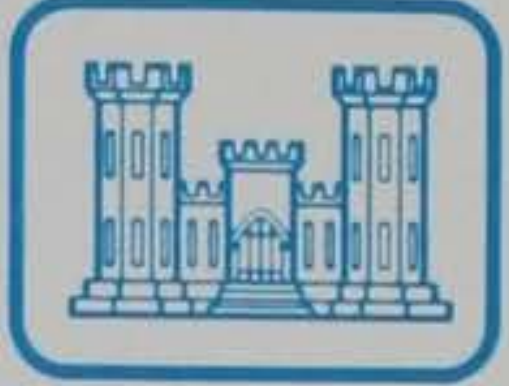

\title{
An analysis of plastic shock waves in snow
}

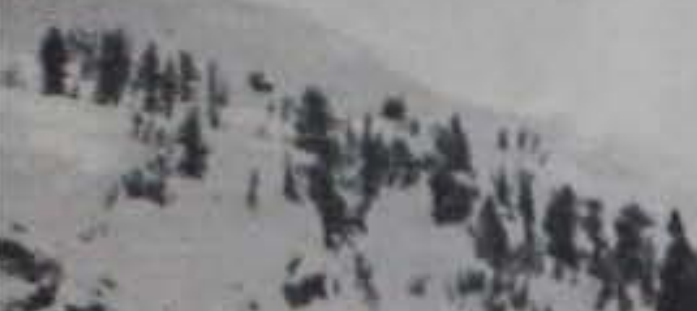

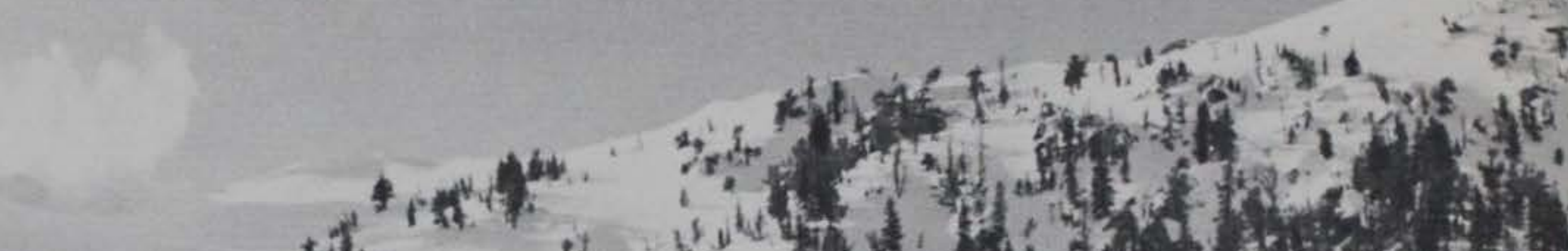

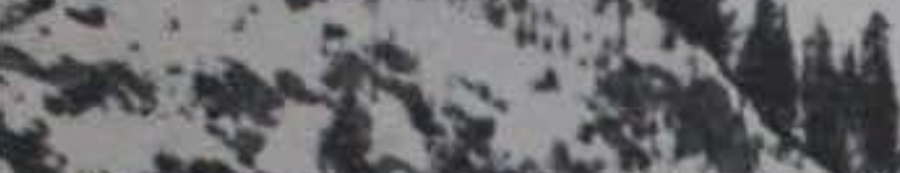

?



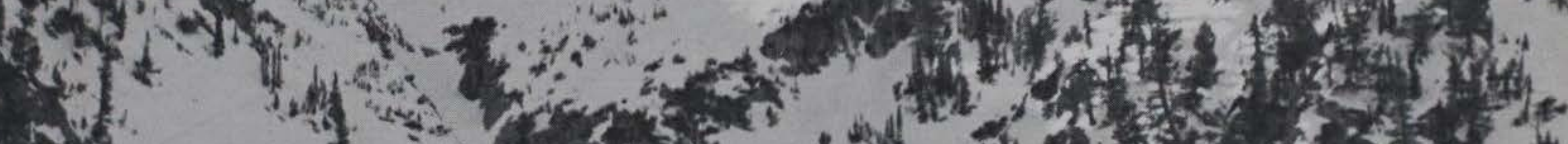



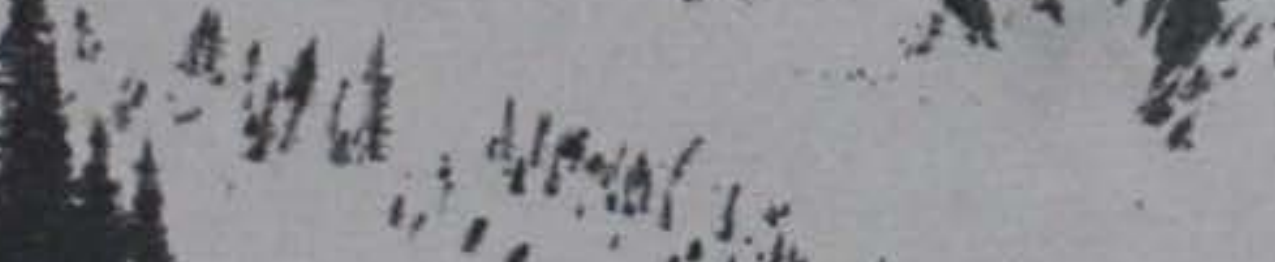



ICIBRARY BRANCH
TECHNICAL INFORMATION CENTER

YICKSBURG MISSISSIPEI 


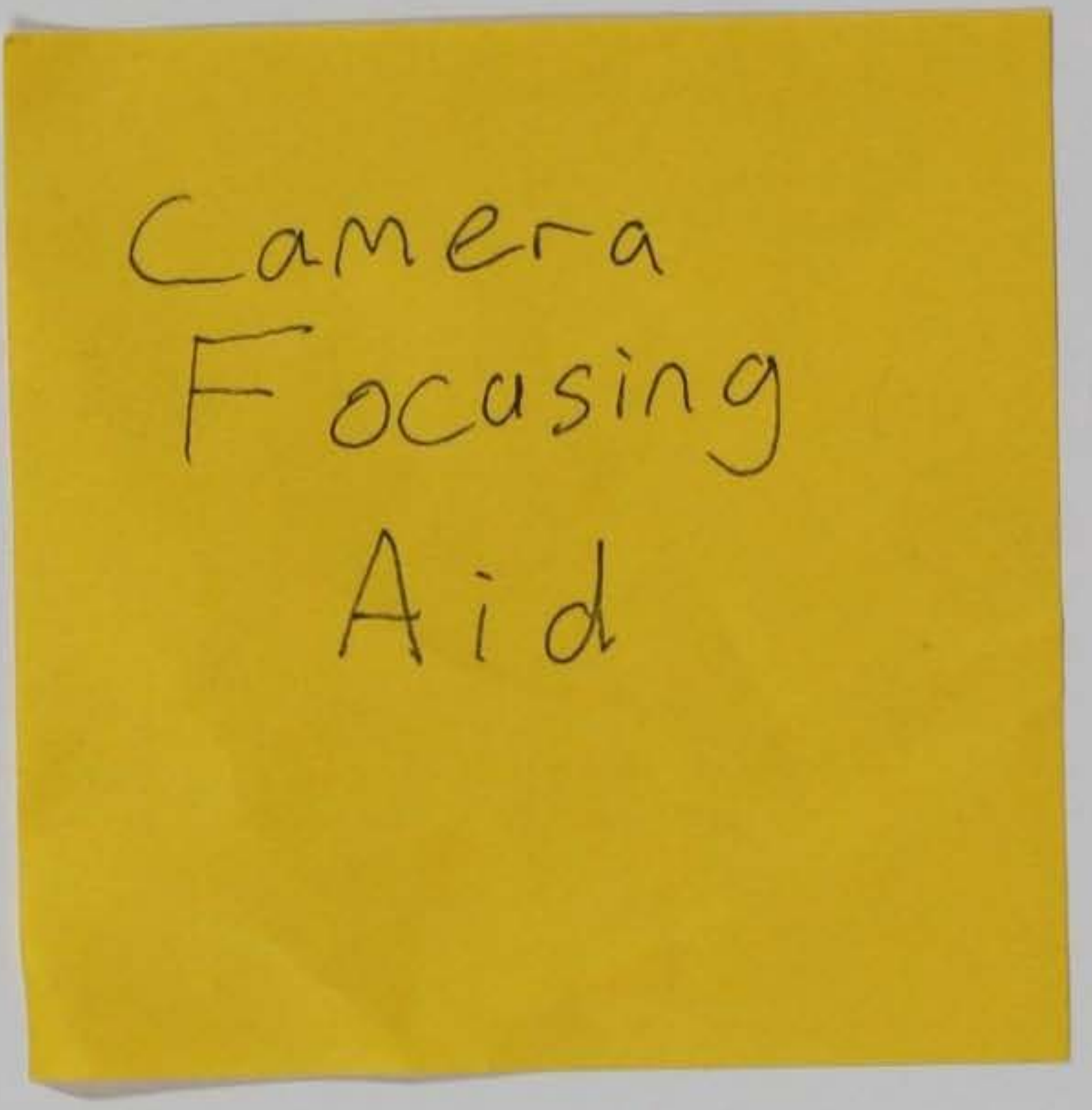

Cover: One application of shock waves in snow. In an attempt to initiate an avalanche in the Bridger Mountains near Bozeman, Montana, approximately 70 pounds of explosive were used to blow cornices off a ridge and onto a $40^{\circ}$ slope. Because of the energy-absorbing capabilities of snow, not all of the cornice was blown free from the ridge. (Photograph by R.G. Oakberg.)

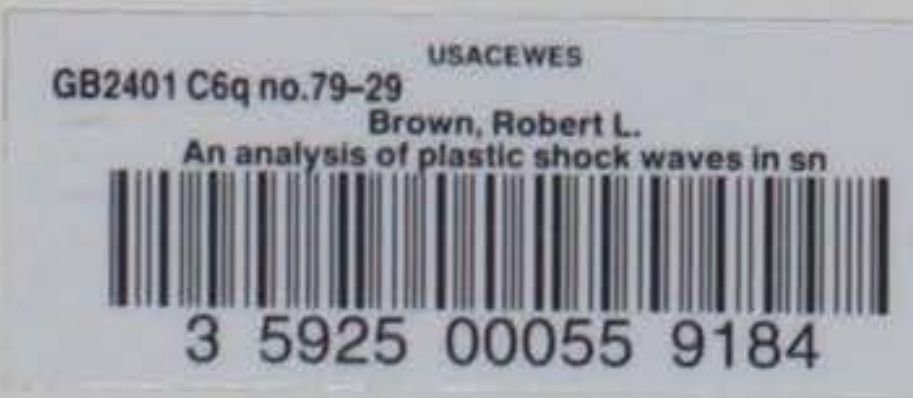




\title{
CRREL Report 79-29
}

\section{An analysis of plastic shock waves in snow}

\author{
Robert L. Brown
}

November 1979

By

UNITED STATES ARMY

CORPS OF ENGINEERS

COLD REGIONS RESEARCH AND ENGINEERING LABORATORY HANOVER, NEW HAMPSHIRE, U.S.A. 


\begin{tabular}{|c|c|c|}
\hline \multicolumn{2}{|c|}{ REPORT DOCUMENTATION PAGE } & $\begin{array}{c}\text { READ INSTRUCTIONS } \\
\text { BEFORE COMPLETING FORM }\end{array}$ \\
\hline $\begin{array}{l}\text { 1. REPORT NUMBER } \\
\text { CRREL Report 79-29 }\end{array}$ & 2. GOVT ACCESSION NO. & 3. RECIPIENT'S CATALOG NUMBER \\
\hline \multirow{2}{*}{\multicolumn{2}{|c|}{$\begin{array}{l}\text { 4. TITLE (and Subtitie) } \\
\text { AN ANALYSIS OF PLASTIC SHOCK WAVES IN SNOW }\end{array}$}} & 5. TYPE OF REPORT \& PERIOD COVERED \\
\hline & & 6. PERFORMING ORG. REPORT NUMBER \\
\hline \multicolumn{2}{|l|}{$\begin{array}{l}\text { 7. AUTHOR(a) } \\
\text { Robert L. Brown }\end{array}$} & $\begin{array}{l}\text { 8. CONTRACT OR GRANT NUMBER(s) } \\
\text { ARO Grant } \\
\text { DRXRO-GS-15413 }\end{array}$ \\
\hline \multicolumn{2}{|l|}{$\begin{array}{l}\text { 9. PERFORMING ORGANIZATION NAME AND ADDRESS } \\
\text { Montana State University } \\
\text { Bozeman, Montana } 59717\end{array}$} & $\begin{array}{l}\text { 10. PROGRAM ELEMENT, PROJECT, TASK } \\
\text { AREA \& WORK UNIT'NUMBERS TASK } \\
\text { DA Project 4A161102AT24 } \\
\text { Task 02, Work Unit } 001\end{array}$ \\
\hline \multirow{2}{*}{\multicolumn{2}{|c|}{$\begin{array}{l}\text { 11. CONTROLLING OFFICE NAME AND ADDRESS } \\
\text { Directorate of Military Programs } \\
\text { Office, Chief of Engineers } \\
\text { Washington, DC } 20314\end{array}$}} & $\begin{array}{l}\text { 12. REPORT DATE } \\
\text { November } 1979\end{array}$ \\
\hline & & $\begin{array}{l}\text { 13. NUMBER OF PAGES } \\
19\end{array}$ \\
\hline \multirow{2}{*}{\multicolumn{2}{|c|}{$\begin{array}{l}\text { 14. MONITORING AGENCY NAME \& ADDRESS(If different from Controlline Office) } \\
\text { U.S. Army Cold Regions Research and Engineering Laboratory } \\
\text { Hanover, New Hampshire } 03755\end{array}$}} & 15. SECURITY CLASS. (of this roport) \\
\hline & & $\begin{array}{l}\text { 15a. DECLASSIFICATION/DOWNGRADING } \\
\text { SCHEDULE }\end{array}$ \\
\hline
\end{tabular}

Approved for public release; distribution unlimited.

17. DISTRIBUTION STATEMENT (of the abstract entered in Block 20, if different from Report)

18. SUPPLEMENTARY NOTES

19. KEY WORDS (Continue on reverse side if necessery and identify by block number)

Plastic shock waves

Shock waves

Snow

Snow loads

20. ABSTRACT (Continue an roveras ofele if necoseary and tdentity by block number)

An analytical study of the propagation of shock waves in snow was carried out to evaluate the response of medium density snow to high rates of loading. One solution was developed for steady shock waves; this resulted in calculation of pressure jump, density jump and stress wave speed. Correlation with available experimental data was found to be good. Nonsteady shock waves were also considered in order to evaluate wave attenuation rates in snow. Very few data were available to compare with the analytical results, so no definite conclusions on the part of the study could be made. The results show, however, that shock waves that produce plastic deformation attenuate at extremely high rates and that differences in pressure between two waves are quickly eliminated within a short distance. Calculations 
20. Abstract (cont'd).

were also made to evaluate the effect of wave frequency on attenuation rates. The results show that, for plastic waves,
frequency is not a predominates.

Camera

Focusing

Aid 


\section{PREFACE}

This report was prepared by Dr. Robert L. Brown, Visiting Scientist, Snow and Ice Branch, Research Division, U.S. Army Cold Regions Research and Engineering Laboratory, on sabbatical leave from the Department of Civil Engineering and Engineering Mechanics, Montana State University, Bozeman, Montana.

The study was funded primarily under U.S. Army-ARO Research Grant no. DRXRO-GS-1 5413 to Montana State University. The study was also funded under DA Project 4A161102AT24, Research in Snow, Ice and Frozen Ground; Task 02, Cold Regions Environmental Interactions; Work Unit 001, Quantifications of Cold Regions Terrain and Climatic Parameters.

The author expresses his appreciation to the Army Research Office and to the U.S. Army Cold Regions Research and Engineering Laboratory for their support.

Technical review of this report was performed by Dr. Y. Nakano and Dr. S. Takagi of CRREL.

The contents of this report are not to be used for advertising or promotional purposes. Citation of brand names does not constitute an official endorsement or approval of the use of such commercial products. 


\section{CONTENTS}

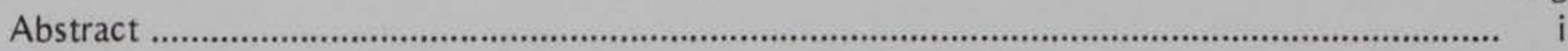

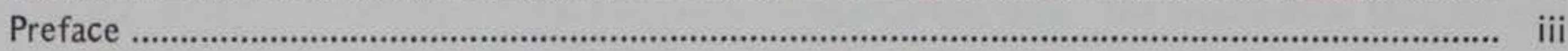



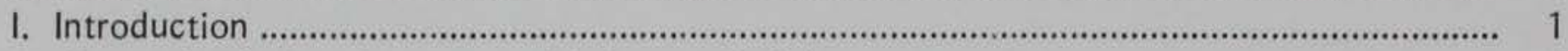

II. A constitutive law for snow and balance principles ...................................................... 2

III. Compatibility laws and jump equations for stress waves ............................................ 3



V. Comparison of steady-wave theory with experimental results ........................................... 6

VI. A numerical solution to the nonsteady wave problem .................................................... 8

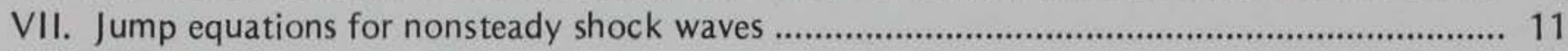

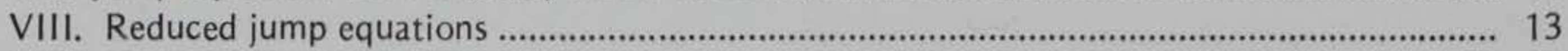

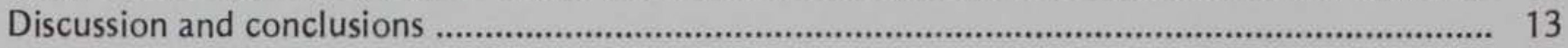

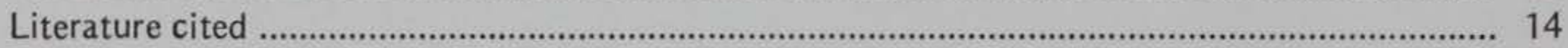

\section{ILLUSTRATIONS}

Figure

1. Pressure jump across wave as a function of density jump........................................... 7

2. Variation of plastic wave velocity with particle velocity ............................................. 7

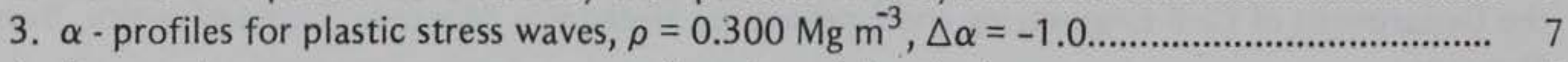

4. Pressure jump across stress wave as a function of density jump................................... 7

5. Variation of plastic wave velocity with pressure jump across wave................................ 8

6. Variation of density jump with time in shock wave............................................... 10

7. Variation of density profile with time in shock wave................................................ 10

8. Density change due to surface loading of snowpack................................................... 10

9. Variation of peak pressure with distance from snowpack surface................................. 10

10. Variation of shock wave speed with distance below surface ........................................... 11

11. Effect of explosive speed on attenuation of shock wave............................................... 11 


\section{NOMENCLATURE}

$\alpha$

$\beta$

$\delta$

$\eta$

$\rho$

$\sigma$

$\tau$

$\phi$

$\omega$

$a_{0}$

A

$A_{1}, A_{2}, A_{3}$

$b_{0}$

$B_{1}, B_{2}, C_{1}$

C

$E_{1}$

$E_{2}$

$E_{\mathrm{p}}$

$E_{\mathrm{T}}$

$f, f_{1}, f_{2}, f_{3}, g$

$F$

$g_{1}$

J

$p$

$Q$

$S_{0}$

$t$

$v$

V

$x$

$X$

W

$Y_{0}$

Y

\section{Superscripts}

t

$+$

-

j

*

\section{Subscripts}

0

i

m

$x$ density ratio $\rho_{\mathrm{m}} / \rho$, eq 2.2

dummy density ratio variable, eq 4.11

differential operator, eq 7.3

steady wave coordinate, eq 4.3

density

normal stress

dynamical constitutive term, eq 2.4

material constant for snow

frequency

initial average void radius in snow

material constant for ice

coefficients in pressure wave jump equation, eq 7.16

body force

coefficients in pressure wave jump equation, eq 7.16

material coefficient for ice

rate modulus, eq 2.7

acceleration modulus, eq 2.8

secant modulus, eq 5.3

tangent modulus, eq 2.6

functions defined by eq 6.8-6.12

integrand function, eq 4.12

function defined by eq 4.10

material coefficient for snow

pressure

dynamical stress term, eq 2.3

material constant for ice

time

particle velocity

stress wave speed

deformed coordinate position of particle

undeformed coordinate position of particle

angular velocity

high-rate yield stress for ice, eq 2.5

coordinate position of stress wave front.

time derivative

derivative with respect to $\eta$

value just ahead of wave

value just behind wave

value at time point $\#$ j, i.e. $t^{i}$

steady value behind steady pressure wave

initial value

value at coordinate position \#i, i.e. at $X_{\mathrm{i}}$

matrix material

in $\mathrm{x}$-direction or $\mathrm{x}$-component. 


\title{
AN ANALYSIS OF \\ PLASTIC SHOCK WAVES IN SNOW
}

\author{
Robert L. Brown
}

\section{INTRODUCTION}

Stress waves in snow are a problem that has not been studied as extensively as other subjects. Practically all of the previous work on the mechanical properties of snow has been restricted to quasi-static conditions in which inertial effects are negligible. Napadensky (1964) first investigated the dynamic properties of snow under the effects of shock waves. More recently, Johnson (1978) considered in detail the propagation of elastic sonic waves in snow. Wakahama and Sato (1977), Wisotski and Snyder (1966), and Gubler (1977) all conducted experimental investigations of stress waves in snow. Mellor (1977) reviewed previous work on shock waves in snow, as did Johnson (1978). But to date virtually no work performed has utilized a material constitutive equation to investigate the propagation of plastic stress waves in snow. This is not surprising, since a valid constitutive law for snow has been lacking, and consequently previous studies have been restricted to the use of mass and momentum balance principles. However, once a constitutive law is found to describe accurately the behavior of snow under rates of loading characteristic of stress waves, a much more detailed analysis of stress waves can be made.

A number of problems require a detailed knowledge of the response of snow to shock waves. The relative effectiveness of in-snow and airborne explosives for initiating avalanches is one such example. To date the relative effectiveness of explosives detonated in the air, or in snowpack, or on the ground has not been determined. Avalanche experts still do not agree on optimum explosive speed or charge size. Another case in which stress waves are generated is projectile impact. A related problem is avalanche impact on structures. In all of these problems, solution of the usual balance principles can yield some information; but without an ap. propriate constitutive law, such questions concerning stress wave attenuation or alteration of stress wave profile cannot be answered.

At this point some definitions are in order. An elastic wave is one in which no internal dissipation takes place. The material responds elastically to the stress wave, and no attenuation can be attributed to inelastic deformation of the material. A plastic wave is one in which material yielding and viscous flow occur. This is often referred to as a nonlinear wave. This is an inexact definition, however, since material nonlinearity can occur in the absence of material yielding and plastic flow. However, since at high deformation rates snow remains practically linear up to the point where yielding begins, any differentiation between plastic waves and nonlinear waves is meaningless.

In stress waves, the jump in a variable (such as strain, pressure, and energy) is defined as the difference between the values of the variable just in front of and behind the wave front. Much of the previous analytical work on stress waves has been restricted to the determination of these jumps. A shock wave is a wave in which the displacement of a particle is continuous across a wave front but in which the particle velocity experiences a jump. An acceleration wave is one in which the particle velocity and displacement are continuous across a wave front, but in which the acceleration has a jump across the wave. The surface representing a wave front is often referred to as a singular surface, since discontinuities in acceleration and/or velocity can occur at this surface.

A steady wave is defined here as one in which the wave speed propagates at a constant speed $V$. One can show that the wave amplitude remains constant for such 
a wave. Even in plastic waves such a condition can be established, al though generally this condition is short-lived. Steady waves have been studied extensively since they are mathematically easy to investigate. Nonsteady waves are simply those waves that lack the characteristics of steady waves; i.e., their amplitudes may either grow or attenuate.

In Section II, a constitutive law developed by Brown (1978a), and used throughout the rest of this report, is briefly discussed. The compatibility laws and jump equations associated with stress waves are then developed in Section III. These laws are applicable to all stress waves irrespective of the material properties. In Section $\mathrm{IV}$, the governing equations for steady shock waves in snow are developed by utilizing the constitutive equation presented in Section II. In Section V, the theory presented in Section IV for steady waves is then compared with existing experimental data and some conclusions are made. Sections VI-VIII are devoted to nonsteady waves. In Section VI, the governing equations are developed, and a direct numerical solution to these equations is then made and compared with existing data. In Section VII, jump equations for nonsteady waves are developed that incorporate the constitutive law for snow. Section VII shows that these equations are extremely complicated for a material such as snow. Then, in Section VIII, some simplifications of these jump equations are made so that they will be more amenable to solution. No solution is attempted, however, since a solution by the finite difference method has already been made in Section VI. However, Section VIII might form the basis for future work on shock waves.

\section{A CONSTITUTIVE LAW FOR SNOW AND BALANCE PRINCIPLES}

Brown (1978a) formulated a constitutive law for volumetric deformations of snow. This formulation was compared with experimental data for strain rates ranging from $10^{-5} \mathrm{~s}^{-1}$ to $10 \mathrm{~s}^{-1}$ and was found to accurately characterize the behavior of snow under large volumetric deformations. The constitutive law (Brown 1978a) is given as a relation between the pressure $p$ and the density ratio $\alpha$ :

$$
\begin{aligned}
& p=\frac{1}{3 \alpha} \ln \left(\frac{\alpha}{\alpha-1}\right)\left\{2\left(S_{0}-C\right)+C \ln \left(\frac{(-\dot{\alpha} A)^{2}}{\alpha(\alpha-1)}\right)\right\} \\
& J \exp \left(-\phi \frac{\alpha}{\alpha_{0}}\right)+\frac{\tau^{2}}{\alpha} \frac{d Q}{d \alpha}(\alpha, \dot{\alpha}, \ddot{\alpha})
\end{aligned}
$$

where $\alpha$ is defined as

$$
\alpha=\rho_{\mathrm{m}} / \rho
$$

$\rho_{\mathrm{m}}$ and $\rho$ are, respectively, the mass density of ice and snow, and $a$ superposed dot implies a time derivative. $S_{0}, C, A, J$ and $\phi$ are all material constants, and $a_{0}$ is the mean initial pore radius of the snow. $Q$ and $\tau^{2}$ are:

$$
\begin{gathered}
Q=-\frac{3}{2} \ddot{\alpha}\left((\alpha-1)^{2 / 3}-\alpha^{2 / 3}\right)-1 / 2 \dot{\alpha}^{2} \\
\left((\alpha-1)^{-1 / 3}-\alpha^{-1 / 3}\right) \\
\tau^{2}=\rho_{\mathrm{m}} a_{0}^{2} /\left(3\left(\alpha_{0}-1\right)^{2 / 3}\right) .
\end{gathered}
$$

The variable $Q$ is significant at extremely high rates of deformation and accounts for the intergranular dynamical effects that must be taken into account for high strain rates such as those generated by shock waves.

The constitutive law was derived by using a pore collapse model similar to the one used in powder metallurgy to study porous metals. The matrix material, ice, is modelled as a rate-sensitive viscoplastic material, and the collapse of a spherical void surrounded by ice under pressure is calculated. This solution is then used to describe the behavior of medium-to-high density snow, with the final result being eq 2.1. The constitutive law has been compared with the data of Abele and Gow (1975) and found to represent accurately the behavior of snow subjected to pressures which result in large increases in density. The constitutive law may be considered valid for initial densities greater than $300 \mathrm{~kg}$ $\mathrm{m}^{-3}$ and values of $\alpha$ ranging from $-10^{-5} \mathrm{~s}^{-1}$ to $10^{4} \mathrm{~s}^{-1}$. The material coefficient $/$ and the material constant $\phi$ must be determined by the snow type and temperature, whereas $S_{0}, C$, and $A$ are fixed by the properties of ice but are still temperature dependent.

Some simplification (Brown 1978b) is possible at high strain rates. This results in

$$
p=\frac{2 Y_{0} J}{3 \alpha} e^{\left(-\phi \alpha / \alpha_{0}\right)} \ln \left(\frac{\alpha}{\alpha-1}\right)+\tau^{2} \frac{d Q}{d \alpha}(\alpha, \dot{\alpha}, \ddot{\alpha}) .
$$

This simplified equation is obviously mathematically more tractable than eq 2.1, and in some situations can be used. $Y_{0}$ is a high strain-rate yield stress for polycrystalline ice and is therefore fixed by the properties of polycrystalline ice.

In the following sections, differentiation of eq 2.1 and 2.5 will be necessary. This can be done in terms of the moduli: 


$$
\begin{aligned}
& E_{\mathrm{T}}=\frac{-\partial p}{\partial \alpha}(\alpha, \dot{\alpha}, \ddot{\alpha}) \\
& E_{1}=\frac{\partial p}{\partial \dot{\alpha}} \\
& E_{2}=\frac{\partial p}{\partial \ddot{\alpha}} .
\end{aligned}
$$

$E_{\mathrm{T}}, E_{1}$, and $E_{2}$ are, respectively, the tangent, rate, and acceleration moduli. The derivatives $\partial p / \partial X$ and $d p / d t$ then can be shown to have the forms:

$$
\begin{aligned}
& \frac{\partial p}{\partial X}=-E_{\mathrm{T}} \frac{\partial \alpha}{\partial X}+E_{1} \frac{\partial \dot{\alpha}}{\partial X}+E_{2} \frac{\partial \ddot{\alpha}}{\partial X} \\
& \frac{d p}{d t}=-E_{\mathrm{T}} \dot{\alpha}+E_{1} \ddot{\alpha}+E_{2} \ddot{\alpha}
\end{aligned}
$$

where $X$ is a coordinate variable.

Consider now balance laws for stress waves. We use here strictly a mechanical theory and do not study restrictions invoked by the energy law or the second law of thermodynamics. The two laws we consider are those of mass balance and momentum balance,

The momentum balance for a plane wave propagating in the $X$ direction requires

$$
\frac{\partial \sigma_{x}}{\partial X}+\rho_{0} b_{0}=\rho_{0} \frac{\partial v}{\partial t}
$$

where $b_{0}$ is the body force acting in the $X$ direction and $v$ is the particle velocity.

If the state of stress is dominated by the pressure $p$, and if body forces are negligible, eq 2.11 can be reduced to:

$$
\frac{-\partial p}{\partial X}=\rho_{0} \frac{\partial \nu}{\partial t}
$$

The mass balance equation (or continuity equation) is

$$
\frac{\rho_{0}}{\rho} \frac{\partial \rho}{\partial t}+\frac{\partial \nu}{\partial X}=0
$$

Since $\alpha=\rho_{\mathrm{m}} / \rho=\rho_{0} \alpha_{0} / \rho$, we can get

$$
\frac{\partial v}{\partial X}=\frac{1}{\alpha_{0}} \frac{\partial \alpha}{\partial t}
$$

as the form of the mass balance equation which is used later.

\section{COMPATIBILITY LAWS AND JUMP EQUATIONS FOR STRESS WAVES}

Consider a one-dimensional stress wave propagating through a medium such as snow. We define as a wave (or wave front) a smooth one-parameter family of points $Y(t),-\infty<t<\infty$, such that $Y(t)$ gives the material point (or particle $X$ ) at which the wave is located at time $t$. $X$ is the position of a particle in the reference configuration, which here will be the undeformed configuration. $x=x(X, t)$ is the position of a particle $X$ at time $t$ and is therefore the deformed position. The intrinsic velocity of the wave is

$$
V=\frac{d}{d t} Y(t)
$$

which is the velocity of propagation relative to the un. deformed position of the body.

Let $f$ be any variable, say density or stress. Assume $f(X, t)$ is a function of position $X$ and time $t$ and is of class $C_{2}$ in $X$ and $t$ except at $X=Y$, where $f$ has a jump discontinuity; i.e., the values of $f$ just in front of and behind the wave front $(X=\eta)$ have different values. We denote this jump by the expression $[f]$, or

$$
[f]=f^{-}-f^{+}
$$

where

$$
\begin{gathered}
f^{-=}=\lim _{X \rightarrow Y} f(X, t) \\
X<Y \\
f^{+}=\lim _{X \rightarrow Y} f(X, t) \\
X>Y .
\end{gathered}
$$

$f^{+}$and $f^{-}$represent, respectively, the values of $f$ just in front of and just behind the wave front. For instance, in a shock wave we would have $[v] \neq 0,[i] \neq 0$, and $[x]=0$; i.e., the particle velocity and particle acceleration would undergo a jump across the shock wave, but particle position would not. The above equations were all defined with the assumption that $V>0$, so that the wave is propagating in the positive coordinate direction.

Now, consider derivatives of $[f]$, since these will be used later in the analysis of shock waves. Assume $f(X, t)$ has a jump discontinuity at the wave front, $X=Y(t)$, but otherwise is continuous and differentiable. Thus, clearly the jump $[f]$ is a function of time only through the position $X=Y(t)$. The derivative of $[f]$ follows from the definition of the jump: 


$$
\begin{aligned}
\frac{d}{d t}[f] & =\frac{d}{d t}\left\{f\left(Y^{-}(t), t\right)-f\left(Y^{+}(t), t\right)\right\} \\
& =\frac{\partial f\left(Y^{-}, t\right)}{\partial X} \frac{d Y}{d t}+\frac{\partial f^{-}}{\partial t} \\
& -\frac{\partial f\left(Y^{+}, t\right)}{\partial X} \frac{d Y}{d t}-\frac{\partial f^{+}}{\partial t}
\end{aligned}
$$

from which we get

$$
\frac{d}{d t}[f]=V\left\lceil\frac{\partial f}{\partial X}\right\rceil+\left\lceil\frac{\partial f}{\partial t}\right\rceil .
$$

However, if we assume $f$ is continuous across the wave front, then $[f]=0$, and eq 3.5 gives

$$
V\left[\frac{\partial f}{\partial X}\right]=-\left[\frac{\partial f}{\partial t}\right]
$$

Equation 3.6 places restrictions on the jumps in the derivatives of $f$ if $f$ is continuous at $Y$. Equation 3.6 is called Maxwell's theorem, al though both eq 3.5 and 3.6 are also often referred to collectively as the compatibility conditions for singular surfaces.

The compatibility equations can now be applied to the balance laws. Recalling that a shock wave generates jump discontinuities in $v, \dot{v}$ and $\partial v / \partial X$, whereas $x$ itself is continuous across the wave, Maxwell's theorem gives

$$
[v]=-V\left[\frac{\partial x}{\partial X}\right] .
$$

To calculate the pressure jump across a pressure wave, integrate eq 2.12 from $X_{\alpha}$ to $X_{\beta}$, where $X_{\alpha} \leqslant Y(t) \leqslant X_{\beta}$, to obtain

$$
-\left\{p\left(X_{\beta}, t\right)-p\left(X_{\alpha}, t\right)\right\}=\frac{d}{d t} \int_{X_{\alpha}}^{X_{\beta}} \rho_{0} \dot{x} d X .
$$

Or, by breaking the integral on the right-hand side into two parts, we get

$$
\begin{aligned}
& -p\left(X_{\beta}, t\right)+p\left(X_{\alpha}, t\right)= \\
& \frac{d}{d t}\left(\int_{X_{\alpha}}^{Y(t)} \rho_{0} \dot{x} d X+\int_{Y(t)}^{X_{\beta}} \rho_{0} \dot{x} d X\right) .
\end{aligned}
$$

Now, taking the limits of $X_{\alpha} \rightarrow \gamma^{-}(t), X_{\beta} \rightarrow \gamma^{+}(t)$, and using eq 3.1 and Leibnitz's rule to differentiate the integral on the right-hand side, we obtain

$$
[p]=\rho_{0} V[\dot{x}]=\rho_{0} V[V] \text {. }
$$

This equation is a familiar jump equation that relates the pressure jump across the wave to the jump in the particle velocity and wave speed. A similar procedure applied to eq 2.14 results in

$$
[\nu]=\frac{-V}{\alpha_{0}}[\alpha]
$$

Therefore, we see that the material has a jump in $\alpha$ if the wave is a shock wave, since $[v]$ is nonzero. Combining eq 3.9 and 3.10 gives

$$
[p]=-\frac{\rho_{0} V^{2}}{\alpha_{0}}[\alpha]
$$

which is a well known relationship for shock waves relating pressure jump across a wave to the jump in density ratio.

Evaluating eq 2.12 both ahead of and behind the wave front, then letting $X$ approach $Y(t)$ and subtracting these two forms of eq 2.12 lead to:

$$
\left[\frac{\partial p}{\partial X}\right]=-\rho_{0}[\dot{v}] \text {. }
$$

Equations $3.9-3.12$ are all widely recognized jump equations for stress waves and are applicable to both steady and nonsteady waves.

We now analyze in detail the propagation of steady waves before considering the details of nonsteady stress waves.

\section{STEADY SHOCK WAVES IN SNOW}

To investigate further the properties of steady waves we now return to the jump equations, eq $3.9-3.11$. If the material is at rest just prior to the stress wave arrival, the jumps $[p]$ and $[v]$ equal the values of $p$ and $v$ as the wave passes. Denoting the steady values of $\alpha$ and $p$ behind the wave by the asterisk, *, eq 3.12 and 3.9 can be put in the following respective forms:

$$
\begin{aligned}
& \alpha^{*}=\alpha_{0}-\frac{\alpha_{0}}{\rho_{0} V^{2}} p^{*} \\
& \nu^{*}=\frac{1}{\rho_{0} V} p^{*} .
\end{aligned}
$$


From here on an asterisk will denote the value of a variable behind the wave, i.e., in the steady condition after the wave has passed. The terms $\nu, \alpha$ and $p$ refer to the values of the respective variables at any point in the wave. As indicated earlier, eq 4.1 and 4.2 result strictly from consideration of the balance principles and do not involve the material properties in any way. We now investigate the effect of material properties on the momentum balance equation.

In a steady wave, the solution to the balance equations may be expressed in terms of the single variable

$$
\eta=X-V t \text {. }
$$

Substituting the constitutive law (eq 2.1) into eq 3.11, and changing variables from $X$ and $t$ to $\eta$ by use of eq 4.3 we find after some algebra

$$
\begin{gathered}
-\frac{\rho_{0} V^{2}}{\alpha_{0}}\left(\alpha-\alpha_{0}\right)=\frac{\jmath}{3 \alpha} \mathrm{e}^{-\phi \alpha / \alpha_{0}} \ln \left(\frac{\alpha}{\alpha-1}\right) \\
\left\{2\left(S_{0}-C\right)+C \ln \left(\frac{\left(-A \alpha^{\prime}\right)^{2}}{\alpha(\alpha-1)}\right)\right\} \\
-\frac{V^{2} \tau^{2}}{2 \alpha} \frac{d}{d \alpha}\left(Q\left(\alpha, \alpha^{\prime \prime}, \alpha\right)\right) .
\end{gathered}
$$

The prime denotes differentiation with respect to the variable $\eta$. After integrating the above, we get

$$
\begin{aligned}
& -\frac{\rho_{0} V^{2}}{3 \alpha_{0}}\left(\alpha-\alpha_{0}\right)\left(\alpha^{2}-\frac{\alpha_{0}}{2}\left(\alpha+\alpha_{0}\right)\right) \\
& =-\frac{V^{2} \tau^{2}}{2}\left[Q\left(\alpha, \alpha^{\prime}, \alpha\right)+\int_{\alpha_{0}}^{\alpha} \frac{J}{3} \ln \left(\frac{\alpha}{\alpha-1}\right)\right. \\
& \left\{2\left(S_{0}-C\right)+C \ln \left(\frac{\left(A V \alpha^{\prime}\right)^{2}}{\alpha(\alpha-1)}\right)\right\} \mathrm{e}^{-\phi \alpha / \alpha} 0 d \alpha .
\end{aligned}
$$

The above equation describes the density ratio jump across the wave, once the wave speed is known. However, this is an integro-differential equation and would have to be solved by a numerical method or some other approximate method.

In cases where strain rates are not extremely large, eq 4.5 would have to be used, since it makes use of the more complete constitutive equation, eq 2.1. Such would be the case for low-frequency, large-amplitude waves.

If one is considering shock waves, the simplified constitutive law, eq 2.5, can be used in place of eq 2.1, since shock waves generally produce exceptionally large strain rates. Substituting eq 2.5 into eq 3.12 , we obtain

$$
\begin{aligned}
& -\frac{\rho_{0} V^{2}\left(\alpha-\alpha_{0}\right)}{\alpha_{0}}=\frac{2 \gamma_{0}}{3 \alpha} / \ln \left(\frac{\alpha}{\alpha-1}\right) \mathrm{e}^{-\phi \alpha / \alpha_{0}} \\
& -\frac{V^{2} \tau^{2}}{2 \alpha} \frac{d}{d \alpha}[(Q(\ddot{\alpha}, \dot{\alpha}, \alpha)]
\end{aligned}
$$

or, upon integrating,

$$
\begin{aligned}
& -\frac{\rho_{0} V^{2}\left(\alpha-\alpha_{0}\right)}{3 \alpha_{0}}\left(\alpha^{2}-\frac{\alpha_{0}}{2}\left(\alpha+\alpha_{0}\right)\right) \\
& =-\frac{V^{2} \tau^{2}}{2}\left[Q\left({ }^{\prime \prime}, \alpha^{\prime}, \alpha\right)\right] \\
& +\int_{\alpha_{0}}^{\alpha} \frac{2 \int Y_{0}}{3} \ln \left(\frac{\alpha}{\alpha-1}\right) \mathrm{e}^{-\phi \alpha / \alpha_{0}} d \alpha .
\end{aligned}
$$

In steady waves, $\alpha=0$ and $" \alpha=0$ both ahead of and behind the wave; therefore $\left[Q\left({ }^{\prime \prime}, \alpha, \alpha\right)\right]$ vanishes. Substituting eq 3.9 into eq 4.7 for steady waves then gives

$$
\begin{aligned}
p^{*}= & \left(2 \int \gamma_{0} \int_{\alpha_{0}}^{\alpha^{*}} \ln \left(\frac{\alpha}{\alpha-1}\right) \mathrm{e}^{-\phi \alpha / \alpha} d \alpha\right) \\
& \left(\alpha^{* 2}-\frac{\alpha_{0}}{2}\left(\alpha^{*}+\alpha_{0}\right)\right)^{-1}
\end{aligned}
$$

Carrying out the indicated integration results in

$$
\begin{aligned}
p^{*}= & \left(\alpha^{* 2}-\frac{\alpha_{0}}{2}\left(\alpha^{*}+\alpha_{0}\right)\right)^{-1} \\
& \left\{g_{1}\left(\alpha^{*}\right)-\mathrm{e}^{-\phi \alpha^{*} / \alpha_{0}} g_{1}\left(\alpha^{*}-1\right)\right\}
\end{aligned}
$$

where

$$
\begin{array}{r}
g_{1}\left(\alpha^{*}\right)=-\frac{\alpha_{0}}{\phi}\left(\ln \left(\alpha^{*}\right) \mathrm{e}^{-\phi \alpha^{*} / \alpha_{0}}-\ln \left(\alpha_{0}\right) \mathrm{e}^{-\phi}\right)+\frac{\alpha_{0}}{\phi} \\
\left(\ln \frac{\alpha}{\alpha_{0}}+\sum_{i=1}^{\infty} \frac{(-\phi)^{n}}{n \cdot n !}\left(\begin{array}{l}
\alpha^{*} \\
\alpha_{0}
\end{array}\right)^{n}-1\right) .
\end{array}
$$

Equations 4.9 and 4.10 give the pressure jump across the wave. Equation 4.6 can then be used to calculate the wave profile, i.e., the variation of the density ratio $\alpha$ inside the stress wave. This can be accomplished by 
inverting eq 4.6 .

$$
\eta=\int_{\alpha_{0}}^{\alpha} \frac{d \beta}{F\left(\beta, \alpha_{0}, V\right)}
$$

where $\eta$ is the variable defined in eq 4.3 , and

$$
\begin{gathered}
F\left(\beta, \alpha_{0}, V\right)=\frac{1}{\tau V}\left\{\frac{4 / Y_{0}}{3 f(\beta)} \int_{\alpha_{0}}^{\beta} \ln \left(\frac{\beta^{\prime}}{\beta^{\prime}-1}\right) \mathrm{e}^{-\phi \beta^{\prime} / \alpha_{0}} d \beta^{\prime}\right. \\
\left.+\frac{2 \rho_{0} V^{2}}{3 \alpha_{0} f(\beta)}\left(\beta-\alpha_{0}\right)\left(\beta^{2}-\frac{\alpha_{0}}{2}\left(\beta+\alpha_{0}\right)\right)\right\}^{1 / 2} .
\end{gathered}
$$

Setting $\alpha=\alpha^{*}$ in eq 4.11 then gives $\eta_{1}$, the length of the wave, but this equation can also be used to calculate the $\alpha-\eta$ profile during the passing of the wave.

\section{COMPARISON OF STEADY-WAVE THEORY WITH EXPERIMENTAL RESULTS}

Napadensky (1964) conducted an extensive testing program on shock waves in snow at Camp Century. These experiments involved snow with densities generally higher than $300 \mathrm{~kg} \mathrm{~m}^{-3}$. The stress waves were generated by using a low-density explosive to drive a metal plate into solid cylindrical specimens. By varying the amount of explosive and the mass of the driver plate, a wide range of load conditions was achieved. The explosive technique, however, usually has a considerable amount of experimental scatter.

A streak camera was used to record the motion of etch marks on the snow specimen and the driver plate. In this way, both particle velocity $v$ and wave velocity $V$ were recorded photographically. Since the speed of the camera was such that the exposure time was only about $5 \mu$ s, fairly good time resolution was achieved. However, as indicated by Mellor (1977), large errors were incurred in the experimental program. There was very poor resolution at the lower pressure levels, and it is questionable whether or not Napadensky's reduced data accurately reflected the actual stress wave parameters. However, for the intermediate range of stress wave pressures, the data appeared reasonable, since the streak film recordings appeared to have both good time resolution and ability to record particle displacement.

The material coefficients used in the constitutive law, eq 2.5, as determined by Brown (1978a, b), are

$$
\begin{aligned}
Y_{0} & =300 \mathrm{bar} \\
J & =3.07 \\
\phi & =5.28 .
\end{aligned}
$$

Figures 1 and 2 give a direct comparison of the theory and Napadensky's experimental results, and as can be seen the two compare fairly well. Figure 1 shows the pressure jump across the wave as a function of the density jump $\Delta \rho$ caused by the wave. Figure 2 shows the variation of plastic wave velocity $V$ with particle velocity $v^{*}$. For particle velocities above $20 \mathrm{~m} \mathrm{~s}^{-1}$, the data and theory compare nicely, but below that, they deviate significantly. The theoretical curve terminates at the point where the wave ceases to be fully plastic.

The data in Figure 2 at the lower particle velocities are questionable. Napadensky shows the plastic wave velocity decreasing to zero as the wave intensity (as indicated by $v^{*}$, the particle velocity) decreases, and this result defies physical reasoning. For instance, as the intensity of a shock wave decreases, the severity of the plastic deformation should also decrease. As the amount of the plastic deformation becomes less significant, the pressure wave should then begin to acquire characteristics of an elastic wave. Equation 3.11 can be used to find the wave speed:

$$
V^{2}=\frac{\alpha_{0}}{\rho_{0}} \cdot \frac{\Delta p^{*}}{\Delta \alpha^{*}}
$$

If $\Delta p^{*} / \Delta \alpha^{*}$ does not approach zero as the stress wave intensity decreases, $V^{2}$ must remain finite at low plastic strains. One would expect $\Delta p^{*} / \Delta \alpha^{*}$ to acquire a value close to the elastic modulus. This argument is also supported by other analytical work, such as that of Coleman et al. (1964), on the theory of wave propagation in nonlinear materials. In particular, we note the familiar equation

$$
V^{2}=E_{\mathrm{p}} / \rho_{0}
$$

where for shock waves $E_{\mathrm{p}}$ is the instantaneous secant modulus, and for acceleration waves $E_{\mathrm{p}}$ is the instantaneous tangent modulus. In either stress wave, $E_{\mathrm{p}}$ increases as the degree of plastic deformation decreases, i.e., as a smaller percentage of the material is deformed plastically. As a result, $E_{\mathrm{p}}$ approaches $E$, Young's modulus of the material, and $V$ thereby increases to a value close to the elastic wave speed for weak plastic waves.

In the case of strong stress waves that produce complete plastic deformation of the matrix material and large jumps in density, the work-hardening characteristics of the material become important in determining the resulting wave speed. In particular, $E_{\mathrm{p}}$ increases as a result of densification and work-hardening effects, thereby resulting in larger values of $V$ as indicated by eq 5.3. Consequently, a very strong plastic wave has a large wave speed. The above reasoning justifies the 


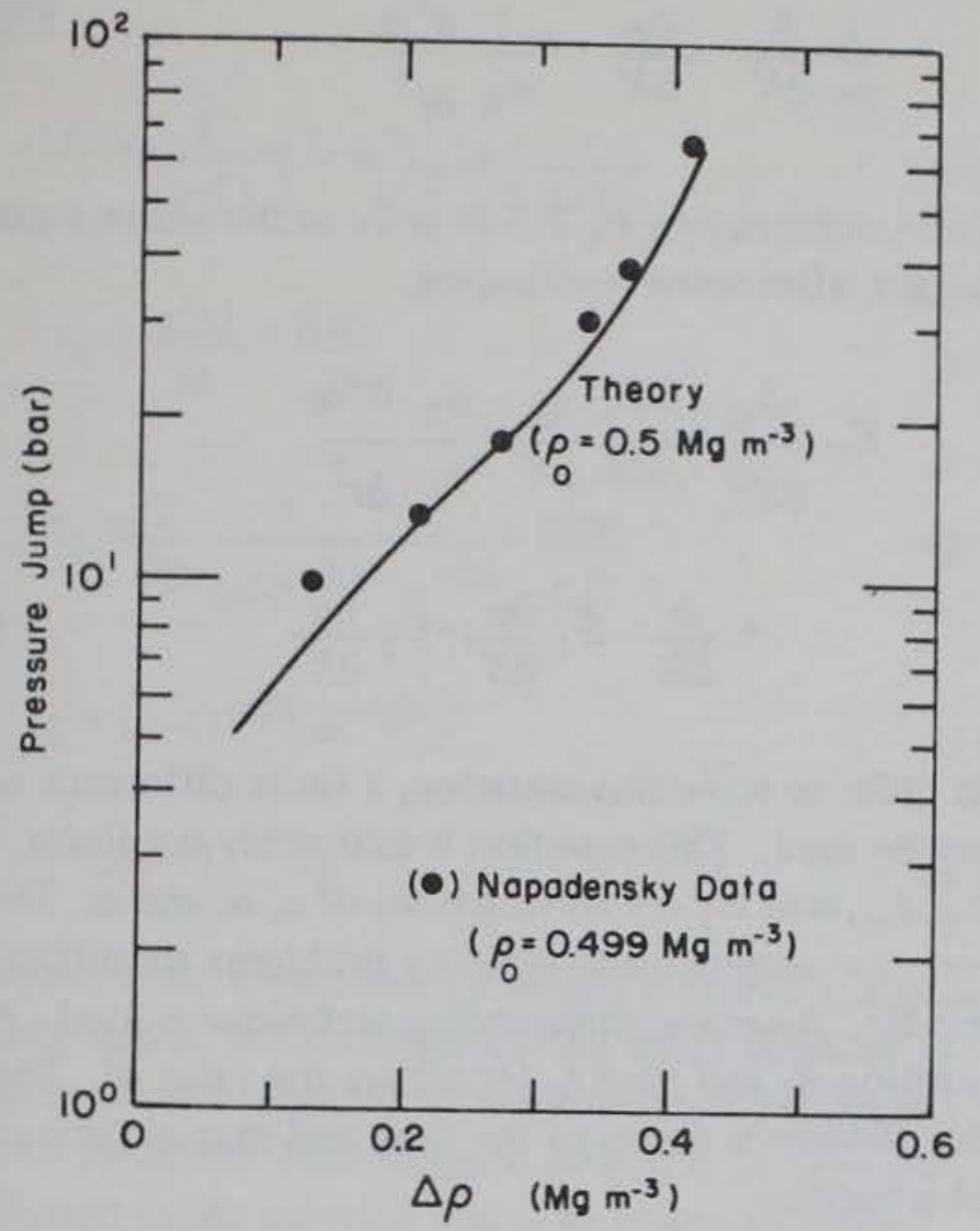

Figure 1. Pressure jump across wave as a function of density jump.

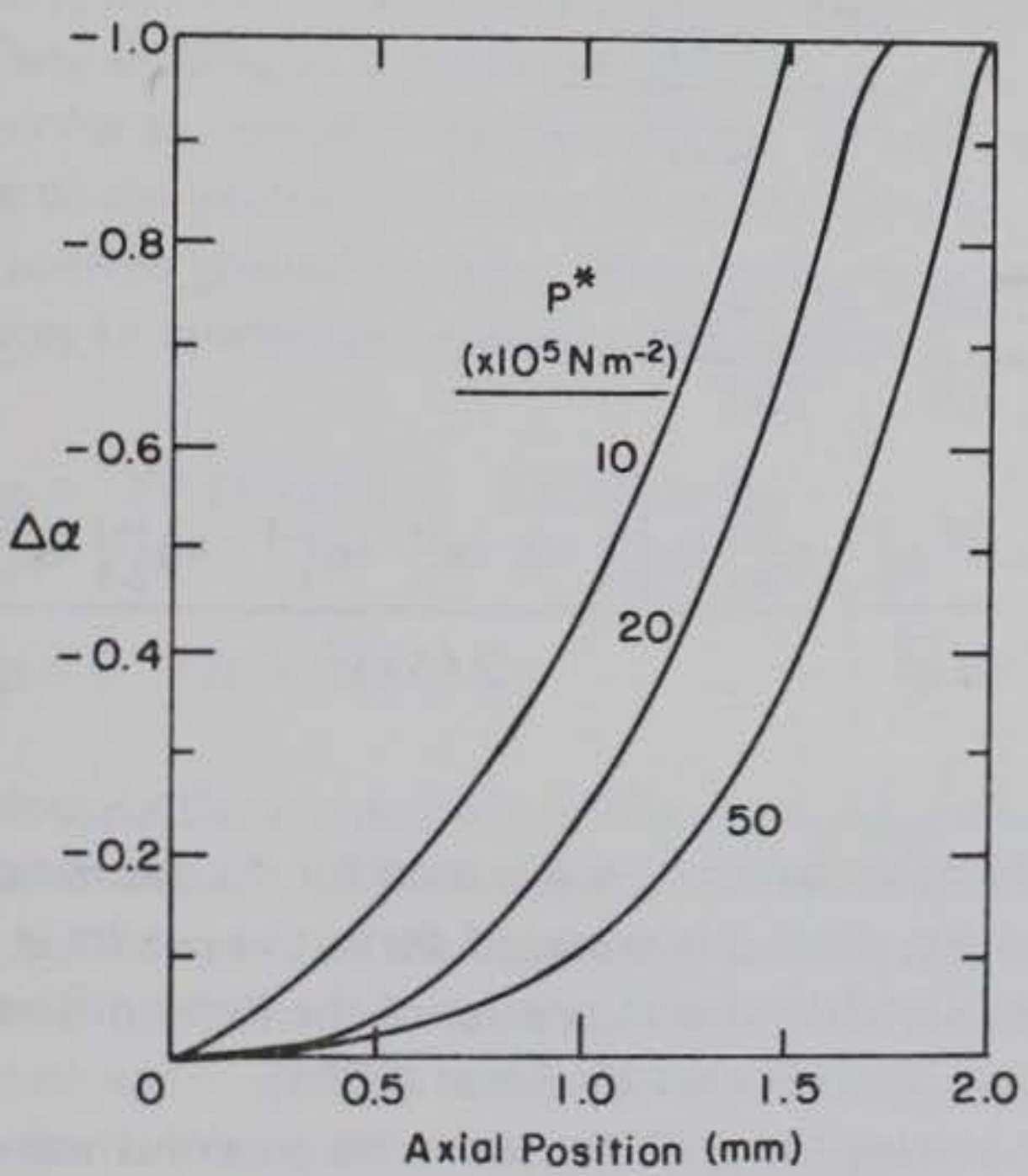

Figure 3. $\alpha$-profiles for plastic stress waves, $\rho=0.300 \mathrm{Mg} \mathrm{m}^{3}, \Delta \alpha=-1.0$.

minimum calculated value of $V$ shown by the curve in Figure 2. This minimum is located near the transition zone between partially plastic and fully plastic waves.

Figures 3 - 5 present results of parametric studies of stress waves in snow. Figure 3 shows how the density ratio varies through the front of the stress wave.

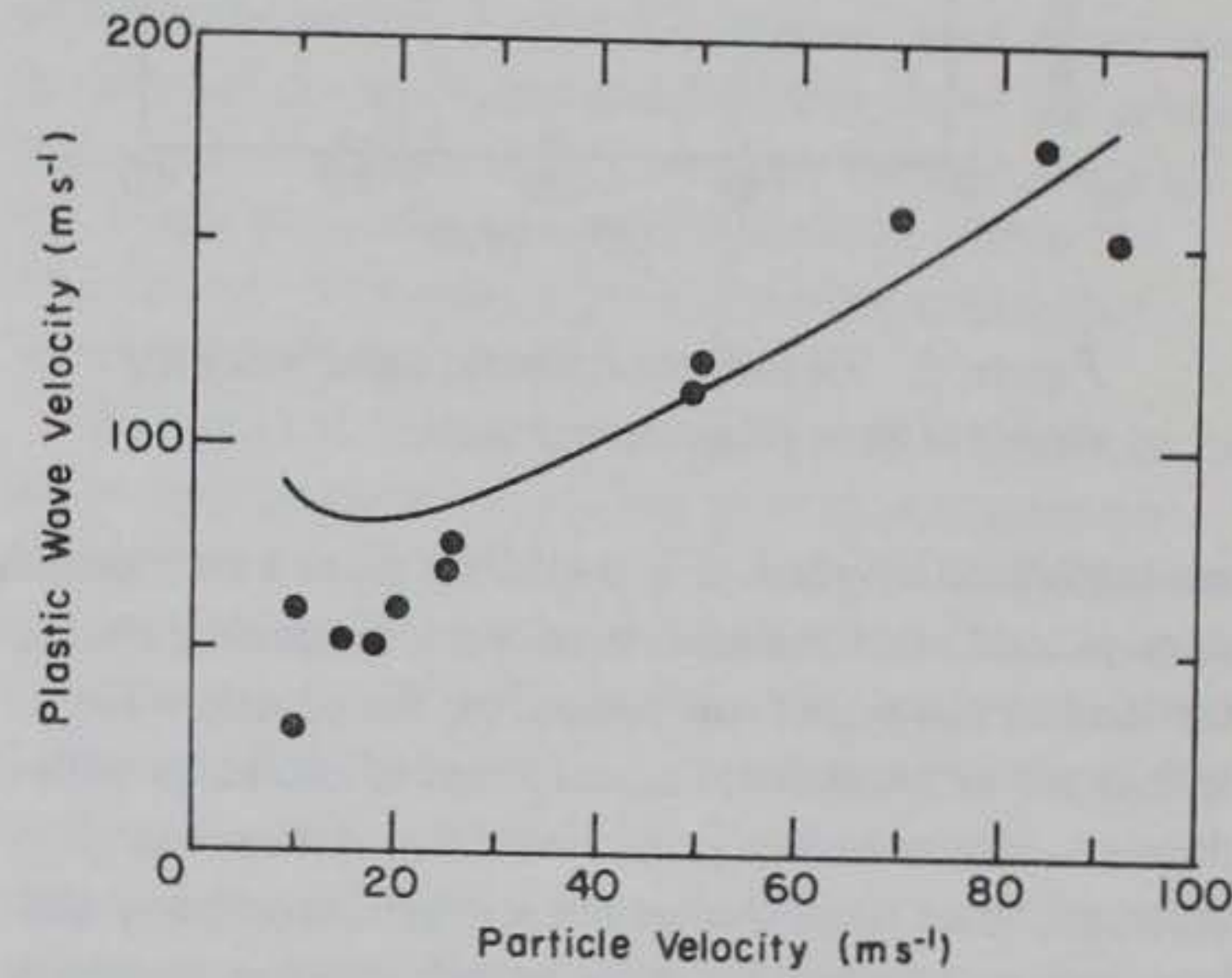

Figure 2. Variation of plastic wave velocity with particle velocity.

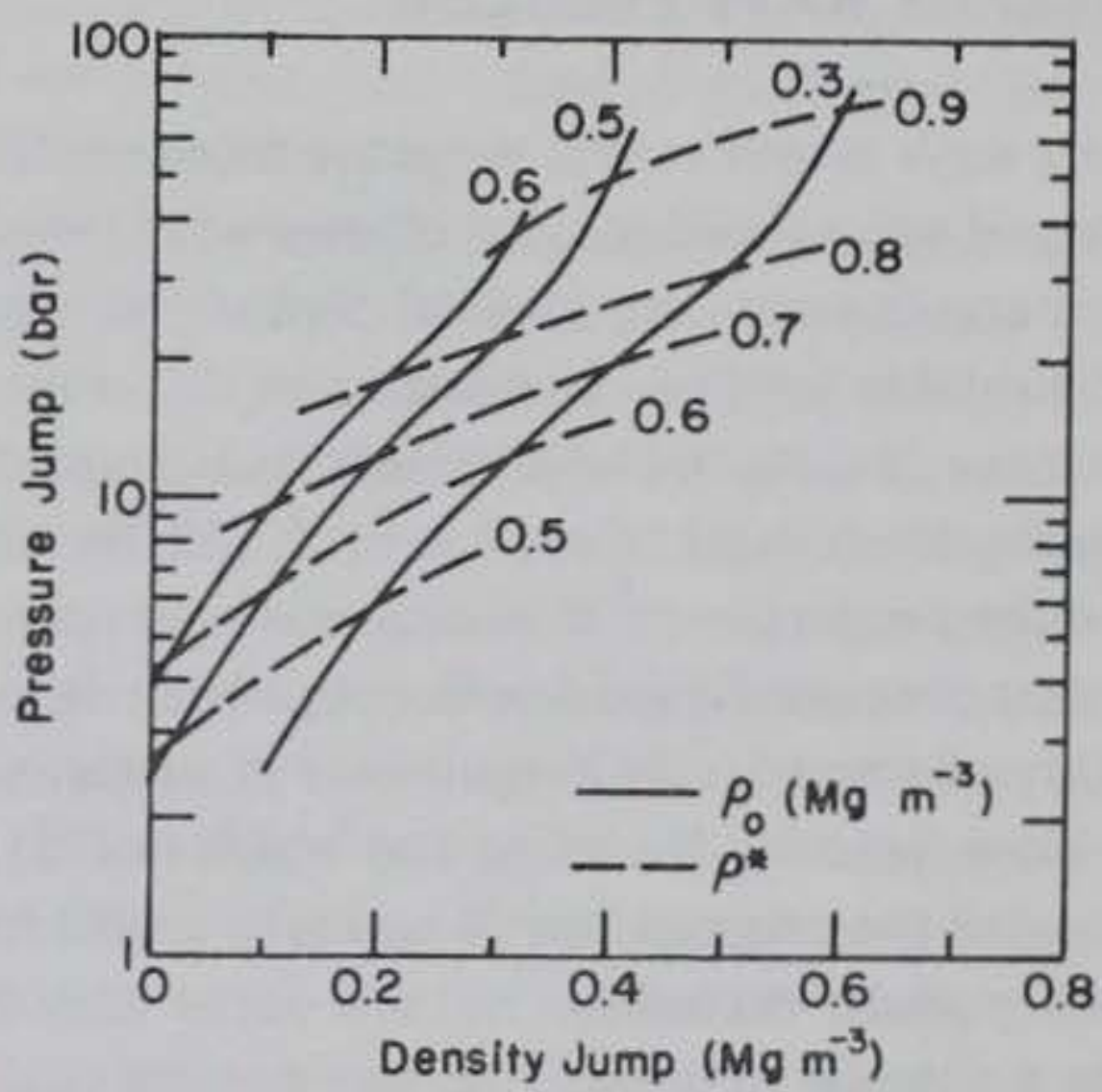

Figure 4. Pressure jump across stress wave as a function of density jump.

For the less intense wave, a shorter wavelength is required to generate the acceleration forces necessary to produce the compaction to decrease $\alpha$ from 3.0 to 2.0.

Figure 4 illustrates the variation of pressure jump $[p]$ with density jump for a range of initial densities. Note that as the initial density is increased, the curves 




Figure 5. Variation of plastic wave velocity with pressure jump across wave.

are translated upward. Figure 5 also gives a very dramatic demonstration of the effects of work-hardening characteristics of snow. At low pressures, the plastic wave speeds are as expected; i.e., wave speed increases with density. But at higher pressures, this relationship is inverted, since large changes in $\alpha$ must accompany the large pressure jumps for snow with initial low densities. Consequently, there is considerable work-hardening, which has a stiffening effect, and this results in increased wave speeds. Snow with high initial densities would not undergo as much work-hardening.

\section{A NUMERICAL SOLUTION TO THE NONSTEADY WAVE PROBLEM}

If the wave is nonsteady, the wave front profile, amplitude and wave speed may all change with time. Material nonlinearity and internal dissipation mechanisms are accountable for this. In some cases, the wave amplitude may actually grow, although such a situation is generally short-lived. Coleman et al. (1964) have studied the properties of nonlinear waves in some detail. Since that time considerable effort has been devoted to the study of stress waves in nonlinear or inelastic materials. More recently, Nunziato and Walsh (1978) have investigated the propagation of waves in uniformly distributed granular materials. In their paper they indicated that, in a granular material, the only density change induced by a shock wave must come from compaction of the matrix material and not from reduction of void volume. This result contradicts the results of this study (eq 3.10) and the experimental results of Napadensky (1964).

We develop now the wave equation for a material with a volumetric constitutive equation of the form given by eq 2.5 .

Differentiating eq 2.14 with respect to time, and then substituting the equation of motion eq 2.12 , yield

$$
\frac{1}{\rho_{0}} \frac{\partial}{\partial X} \frac{-\partial p}{\partial X}=\frac{1}{\alpha_{0}} \frac{\partial^{2} \alpha}{\partial t^{2}}
$$

Then, substituting eq 2.5 directly in the above equation, we get, after some rearranging,

$$
\begin{gathered}
E_{\mathrm{T}} \frac{\partial^{2} \alpha}{\partial X^{2}}+\frac{\partial E_{\mathrm{T}}}{\partial X} \frac{\partial \alpha}{\partial X}=\frac{\rho_{0}}{\alpha_{0}} \frac{\partial^{2} \alpha}{\partial t^{2}} \\
+\frac{\partial}{\partial X} E_{1} \frac{\partial \dot{\alpha}}{\partial X}+E_{2} \frac{\partial \ddot{\alpha}}{\partial X} .
\end{gathered}
$$

In order to solve this equation, a finite difference solution can be used. This equation is extremely nonlinear, since $E_{\mathrm{T}}, E_{1}$, and $E_{2}$ are all functions of $\alpha, \dot{\alpha}$, and $\ddot{\alpha}$. Therefore, convergence and stability problems are difficult to handle. A central differencing technique is used. At position $X_{\mathrm{i}}$ and time $t_{\mathrm{j}}$, let $\alpha$ have the value $\alpha_{\mathrm{j}}^{\mathrm{j}}$. Then the difference forms of the time and spacial derivatives of $\alpha$ become

$$
\begin{aligned}
& \ddot{\alpha}_{i}^{j}=\frac{\alpha_{i}^{j+1}-\alpha_{i}^{j-1}}{2 \Delta t} \\
& \ddot{\alpha}_{i}^{j}=\frac{\alpha_{i}^{j+1}-2 \alpha_{i}^{j}+\alpha_{i}^{j-1}}{(\Delta t)^{2}} \\
& \frac{\partial \alpha_{i}^{j}}{\partial X}=\frac{\alpha_{i+1}^{j}-\alpha_{i-1}^{j}}{2 \Delta x} \\
& \frac{\partial^{2} \alpha_{i}^{j}}{\partial x^{2}}=\frac{\alpha_{i+1}^{j+1}+\alpha_{i+1}^{j-1}-2 \alpha_{i}^{j+1}+\alpha_{i}^{j-1}+\alpha_{i-1}^{j+1}+\alpha_{i-1}^{j-1}}{2(\Delta x)^{2}}
\end{aligned}
$$

The form shown in eq 6.6 is used for the second order derivative, since this averaged derivative results in improved stability characteristics of the finite difference solution, as indicated by Ames (1965).

In solving the problem, a double modulus was employed. During pressure buildup, eq 2.6 gives the appropriate tangent modulus, which becomes

$$
\begin{gathered}
E_{\mathrm{T}}=\frac{2 \gamma_{0} / \mathrm{e}^{-\phi \alpha / \alpha} 0 f_{1}(\alpha)}{3 \alpha^{2}}-\tau^{2} \gamma_{0} \\
f_{2}(\alpha) \ddot{\alpha}-f_{3}(\alpha) \dot{\alpha}^{2}
\end{gathered}
$$


where

$$
\begin{aligned}
& f_{1}=\frac{1}{(\alpha-1)}+\left(1+\phi \frac{\alpha}{\alpha_{0}}\right) \ln \left(\frac{\alpha}{\alpha-1}\right) \\
& f_{2}=\frac{g(\alpha)}{3 \alpha}+\frac{f(\alpha)}{\alpha^{2}} \\
& f_{3}=\frac{2}{9 \alpha} \frac{1}{(\alpha-1)^{7 / 3}}-\frac{1}{\alpha^{7 / 3}}+\frac{g(\alpha)}{6 \alpha^{2}} \\
& g=(\alpha-1)^{-4 / 3}-\alpha^{-4 / 3} \\
& f=(\alpha-1)^{-1 / 3}-\alpha^{-1 / 3} .
\end{aligned}
$$

However, once a maximum pressure is reached, and unloading begins, the static part of $E_{\mathrm{T}}$ must decrease in order to avoid a large elastic rebound in the finite difference solution. This rebound produces an artificial oscillation in the solution and is a common problem with finite difference methods. Various methods have been used to reduce this form of instability. The easiest way to facilitate this is to decrease $f_{1}$ by a factor of $1 / 2$ when $\alpha$ becomes negative. A factor of $1 / 2$ is somewhat arbitrary, but this value was found to be sufficient to avoid any significant volumetric rebound.

In order to demonstrate the solution, we consider the particular problem of an air blast directly over a snow covered ground surface. We assume the blast produces an overburden pressure of the form

$$
\begin{aligned}
& p=\frac{1}{2} p *(1-\cos W t) \quad 0 \leqslant W t \leqslant 2 \pi \\
& p=0 \quad W t \geqslant 2 \pi
\end{aligned}
$$

and calculate the attenuation of the wave as it propagates into the snowpack. The frequency $\omega=W / 2 \pi$ is determined by the speed of the explosion, and the overburden pressure $p *$ is determined by explosive size and proximity to the snowpack surface. Of particular interest is the response of a snowpack to an overburden pressure of about 20 bar since this is what the SLUFAE (surfacelaunched unit fuel air explosive) weapon system generates.*

Figures $6-11$ show results of the finite difference solution of the nonsteady wave problem just described. Figures 6 and 7 illustrate how the wave form is altered as it propagates into snow with an initial density of $350 \mathrm{~kg} \mathrm{~m}^{-3}$. The surface loading has a frequency of $\omega=5000 \mathrm{~Hz}$ and an amplitude of $p^{*}=12 \mathrm{bar}$. Figure

*D.R. Farrell, USACRREL, Private communication.
6 shows the temporal variation of the density change for points at $0,1,2,5$, and $8 \mathrm{~cm}$ into the snowpack. Figure 7 demonstrates the density profile for various times. Note how the wave spreads and the density rates $\rho$ decrease as the wave propagates further into the snow. pack.

Figures 8 and 9 make a direct comparison of three different pressures. Figure 8 compares wave attenuation in terms of density jump and Figure 9 shows the pressure attenuation. As can readily be seen, the advantage of the higher pressures is largely eliminated within the first $10 \mathrm{~cm}$. This merely points out the substantial energy absorbing capability of snow.

As expected, the highly dissipative characteristics of snow rapidly change the stress wave as it propagates through snow. For pressure waves with a magnitude in excess of 5 bar, the pressure amplitude reduced to a small fraction within $10 \mathrm{~cm}$. This result is to some extent verified by Wisotski and Snyder (1966). In the tests reported by Wisotski and Snyder, one-pound spherical Penolite charges were detonated in deep midseason snowpack. Piezoelectric gages were used to record arrival times and pressures to within $0.15 \mathrm{~m}$ of the charge. These transducers apparently had a broad, flat frequency range, so that the recorded results should be meaningful. They also observed that the wave speed close to the charge was significantly slower than further from the charge. However, there was a great deal of scatter in measurement of arrival times, so no precise measurements were made. But the pressure readings for a 6-bar pressure wave showed good agreement with the results shown in Figure 9.

Figure 10 shows the variation of the stress wave speed as the wave propagates into the snow. Initially the 21 . bar wave travels at a significantly higher speed, but this situation quickly changes. The variation in stress wave speed is due to a combination of factors. The wave speeds initially decrease as the waves attenuate and workhardening effects become less significant. However, once the wave intensity is reduced to a critical value, dissipative effects likewise become less significant, and the wave speed begins to increase. These results are in close agreement with those shown in Figure 4 for steady waves.

Figure 11 shows the effect of wave frequency on attenuation. One can readily see that higher frequency waves do attenuate more quickly, but this effect is not all that great. Of the three waves shown, the difference in pressure jump by the $5-\mathrm{cm}$ position is only about $20 \%$. The frequency difference is partly erased by wave spreading, and probably the higher frequency waves spread more quickly and therefore experience a quicker reduction in frequency content.

It is also possible to study the growth and decay of shock waves by considering the jump equations. These 


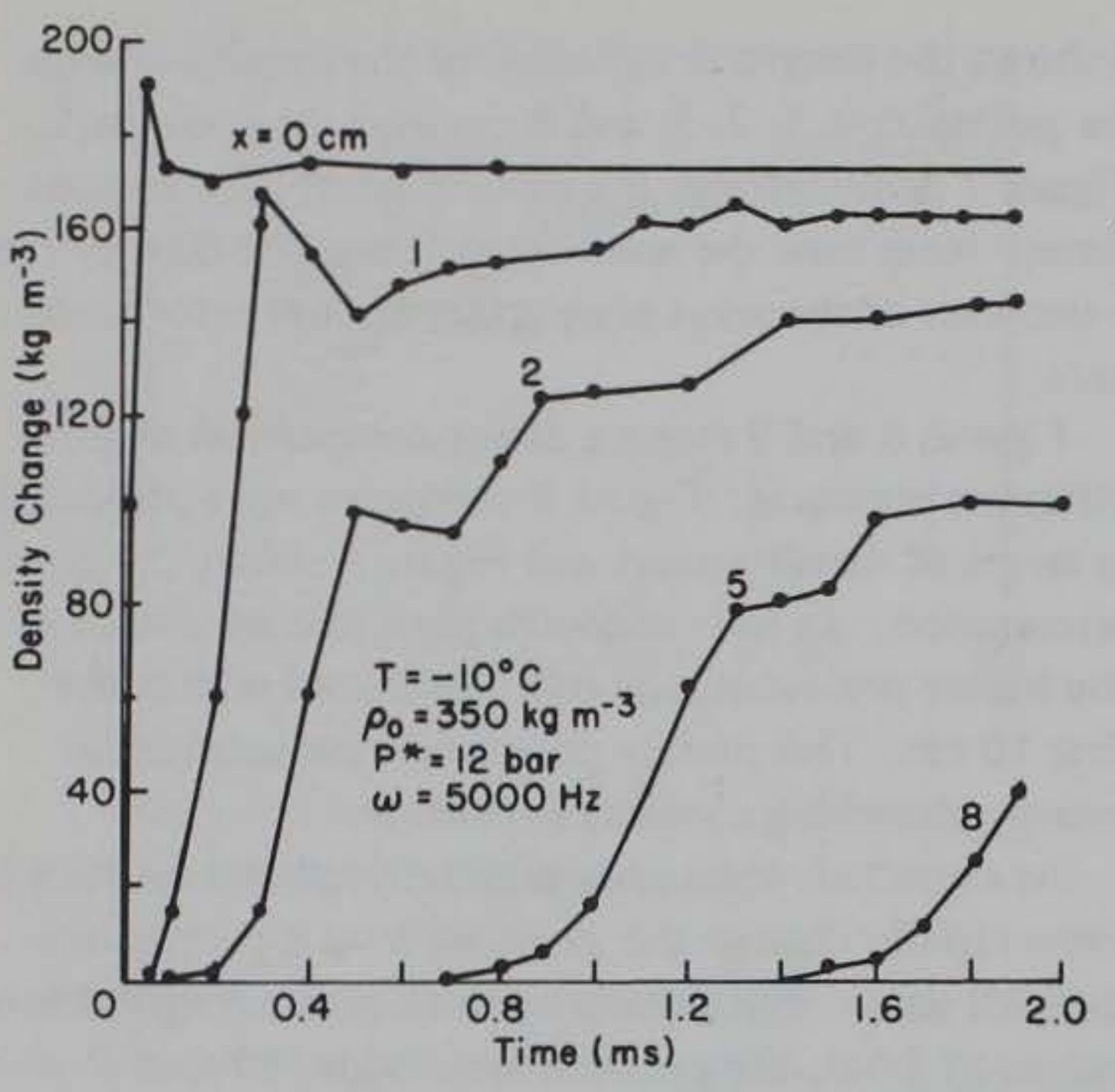

Figure 6. Variation of density jump with time due to surface induced shock wave.

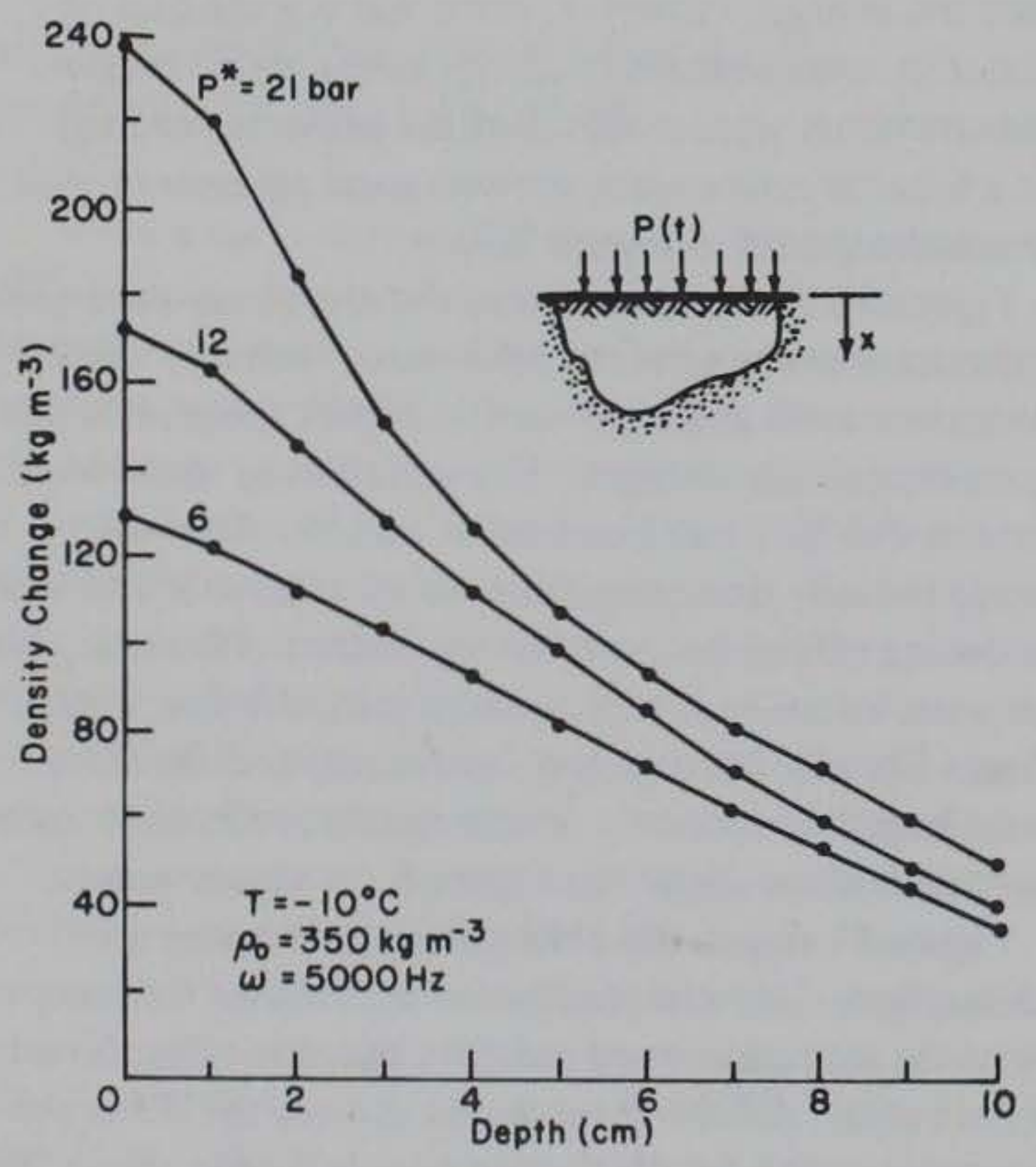

Figure 8. Density change due to surface loading of snowpack.



Figure 7. Variation of density profile with time in shock wave.

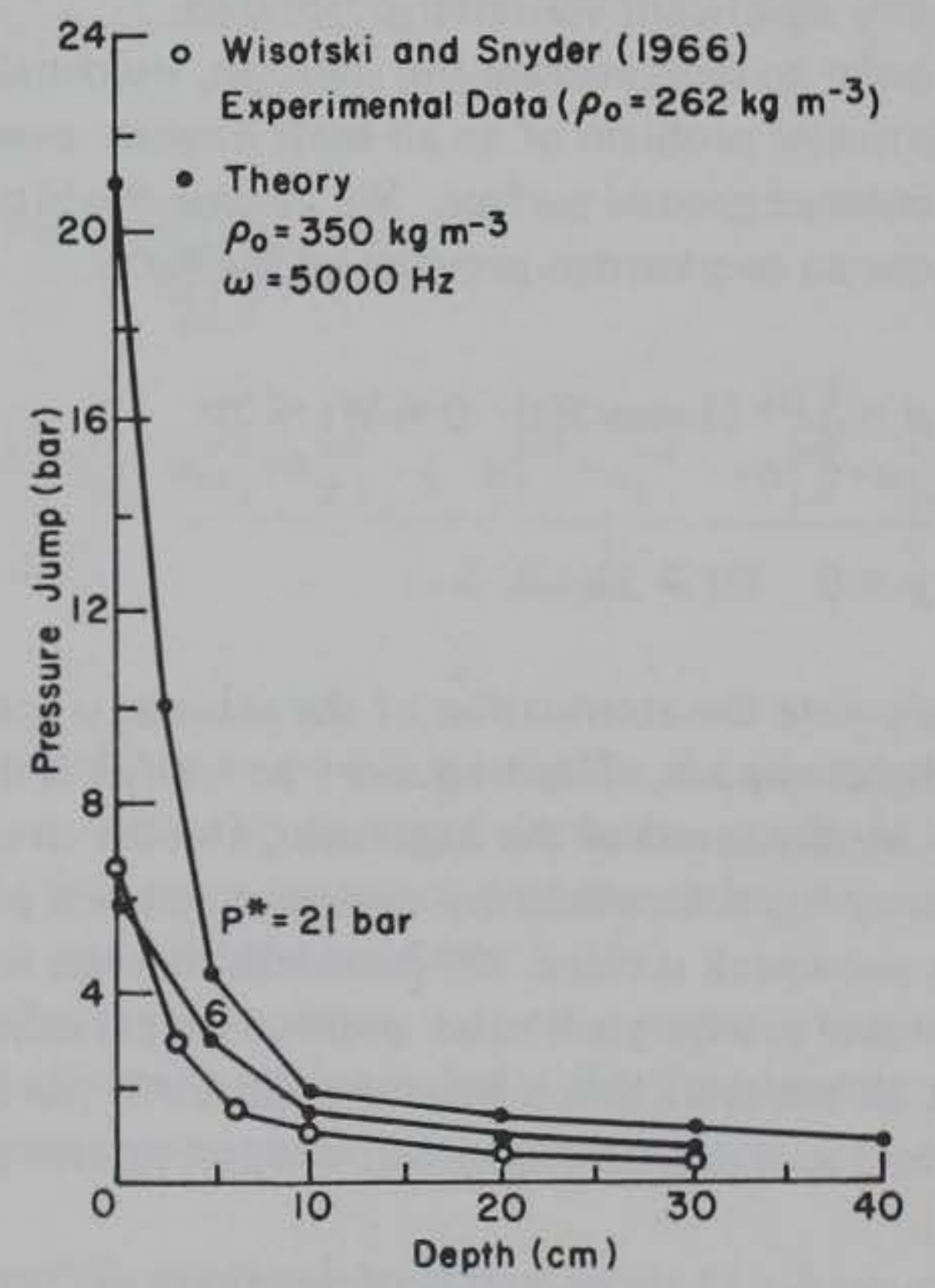

Figure 9. Variation of peak pressure with distance from snowpack surface. 


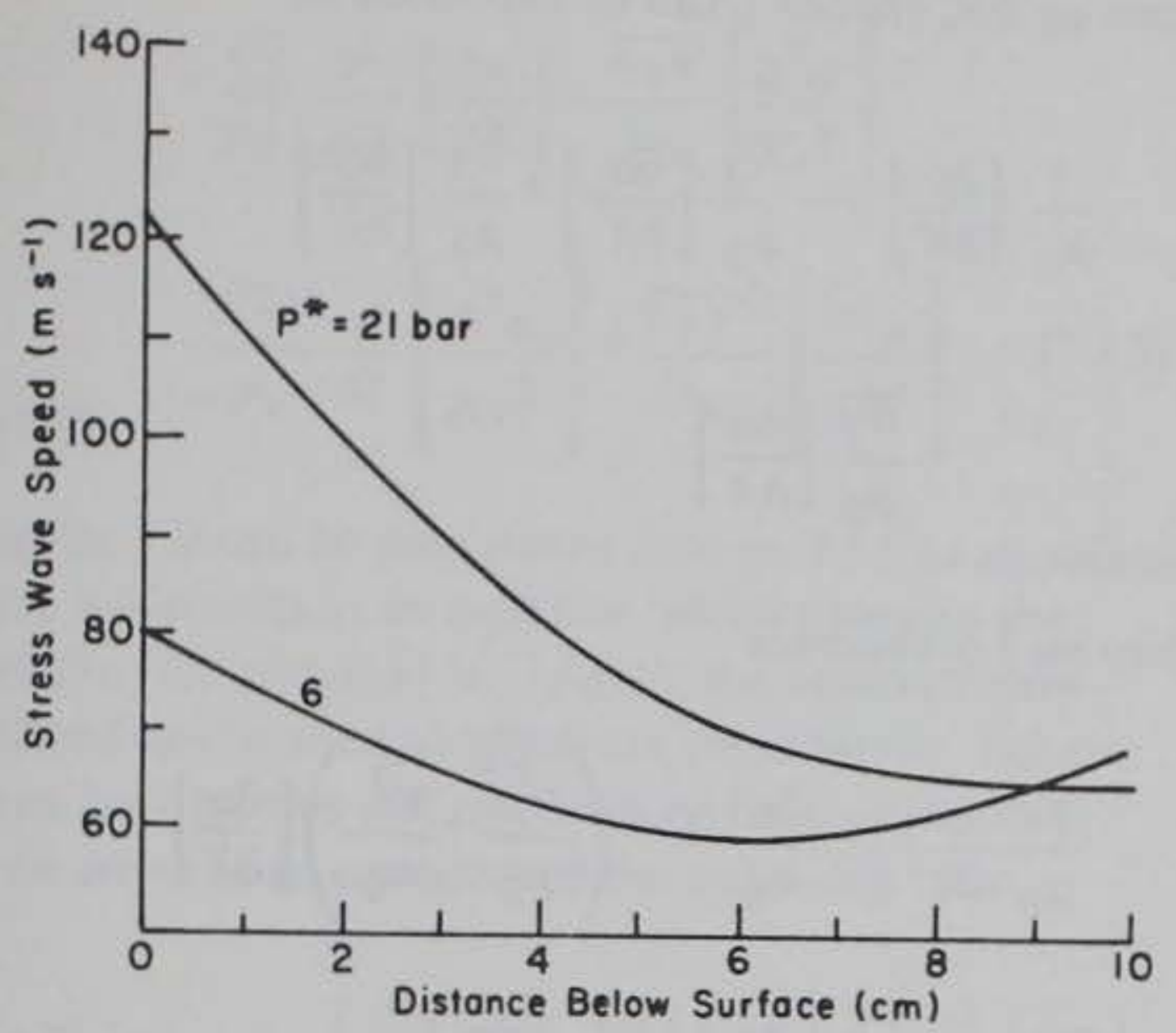

Figure 10. Variation of shock wave speed with distance below surface.

equations cannot give as much information as the direct approach just discussed, since stress wave profile and wave length cannot be calculated from the jump equations. However, the direct approach using the finite-difference technique is computationally a time-consuming and expensive means of solving the problem. If wave attenuation is sought, there should be more convenient means of doing this.

\section{JUMP EQUATIONS FOR NONSTEADY SHOCK WAVES}

For nonsteady waves, the rate of change of the wave amplitude must be calculated to properly characterize the wave. The amplitude of a shock wave can be described in terms of either $[p]$ or $[\alpha]$, since both of these give a measure of the wave intensity. First, we investigate the variation of $[p]$. Letting $f=p$ in eq 3.5 ,

$$
\frac{d}{d t}[p]=V[\partial p / \partial X]+[\partial p / \partial t] .
$$

Then using eq 2.9 and 2.10 , we get

$$
\frac{d}{d t}[p]=-\left[E_{\mathrm{T}} \frac{\delta \alpha}{\delta t}\right]+\left[E_{1} \frac{\delta \dot{\alpha}}{\delta t}\right]+\left[E_{2} \frac{\delta \ddot{\alpha}}{\delta t}\right]
$$

where $\delta / \delta t$ is the differential operator

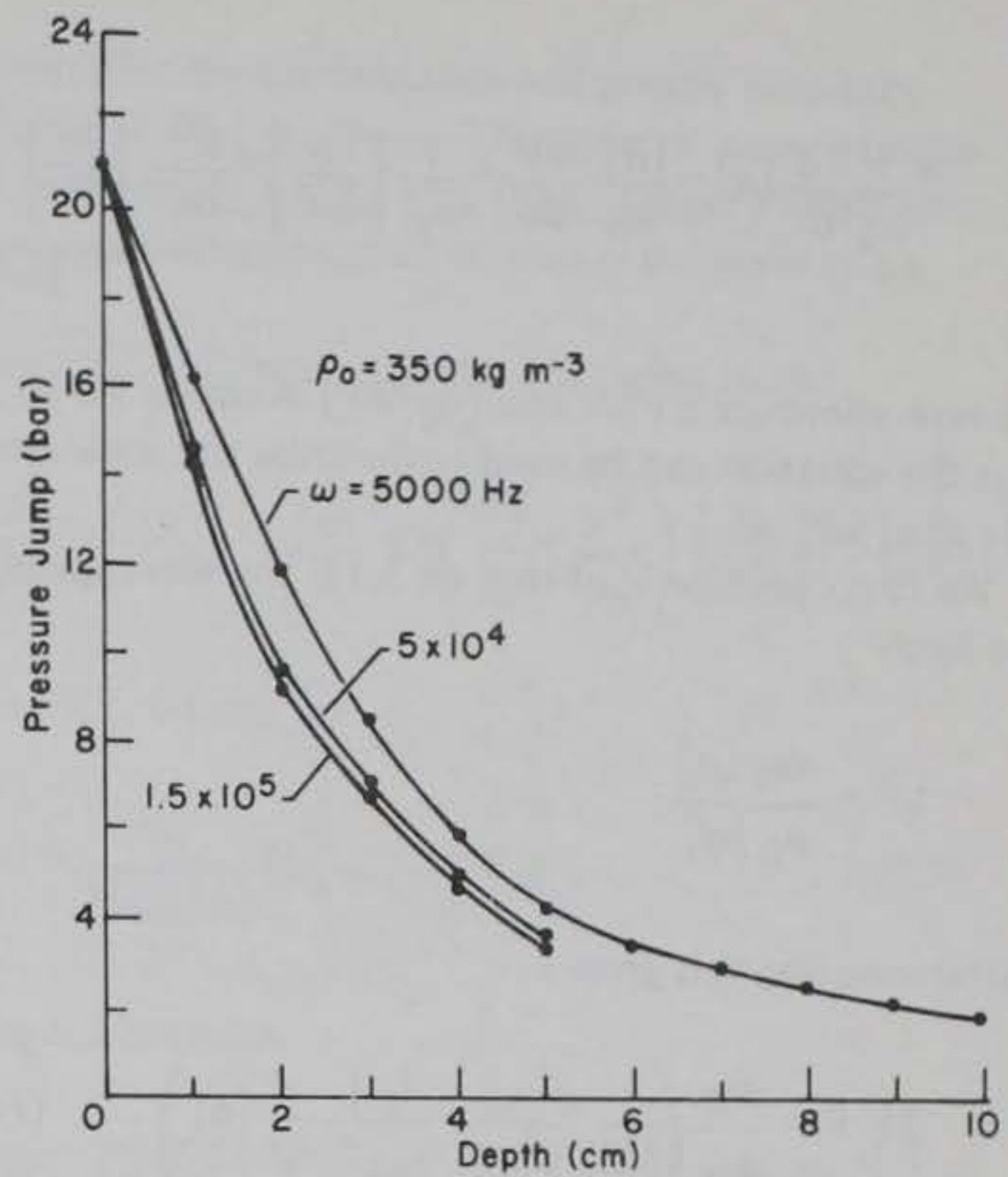

Figure 11. Effect of explosive speed on attenuation of shock wave.

$$
\frac{\delta}{\delta t}=V \frac{\partial}{\partial X}+\frac{\partial}{\partial t} \text {. }
$$

Equation 7.2 gives the growth of the pressure wave in terms of the three moduli and the derivatives of $\alpha, \dot{\alpha}$ and $\ddot{\alpha}$. Unlike elastic waves, the condition for growth or decay of the wave is a complex function of the three moduli and the spatial and temporal variation of $\alpha, \dot{\alpha}$ and $\ddot{\alpha}$ behind the wave.

Now, assume that the stress wave is entering an undeformed medium, such that $p^{+}, \nu^{+}, \partial p^{+} / \partial X$ are all zero; then $[p]$ is just

$$
[p]=p^{-}
$$

Similar relations hold for $\nu^{-}$and $\partial p^{*} / \partial X$. In this case, the jump of a product, $[a b]$, is equal to $a^{*} b^{*}$, i.e., the product of the values behind the wave. Using this result, we see that eq 7.2 becomes

$$
\frac{d}{d t} p^{-}=E_{\overline{\mathrm{T}}}^{-}\left(\frac{\delta \alpha}{\delta t}\right)^{-}+E_{1}^{-}\left(\frac{\delta \dot{\alpha}}{\delta t}\right)^{-}+E_{2}^{-}\left(\frac{\delta \ddot{\alpha}}{\delta t}\right)^{-} .
$$

Equation 7.5 indicates that if conditions behind the wave are steady, i.e., $\alpha$ is constant, $d p^{-} / d t$ vanishes, and the wave amplitude does not change with time. This is not the case with nonsteady waves.

Now, develop a jump relation for $[\alpha]$. Equation 3.10, eq 3.5 with $f=\alpha$ and $f=v$, eq 3.11 , and eq 2.14 can be combined to yield, after considerable algebra, the relation 


$$
2 \frac{V}{\alpha_{0}} \frac{d}{d t}[\alpha]+\frac{[\alpha]}{\alpha_{0}} \frac{d V}{d t}=\frac{1}{\rho_{0}}\left[\frac{\partial p}{\partial X}\right]+\frac{V^{2}}{\alpha_{0}}\left[\frac{\partial \alpha}{\partial X}\right] .
$$

We now eliminate $d V / d t$ and $[\partial p / \partial X]$ from eq 7.6 so that the equation can be used to describe the wave decay rate $d[\alpha] / d t$.

We first consider $\dot{V}$. From eq 3.11 , the wave speed has the form

$$
V^{2}=\frac{-\alpha_{0}[p]}{\rho_{0}[\alpha]}
$$

Differentiating this gives

$$
2 V \dot{V}=\frac{-\alpha_{0}}{\rho_{0}}\left(\frac{1}{[\alpha]} \frac{d[p]}{d t}-\frac{[p]}{[\alpha]^{2}} \frac{d}{d t}[\alpha]\right) \text {. }
$$

Since $[p]=p^{-}=p(\alpha \dot{\alpha} \ddot{\alpha}), d[p] / d t$ can be expressed in the following form:

$$
\begin{aligned}
\frac{d}{d t}[p] & =\left(\frac{\partial p}{\partial \alpha}\right)^{\cdot} \frac{d}{d t}[\alpha]+\left(\frac{\partial p}{\partial \alpha}\right)^{\cdot} \frac{d}{d t}[\dot{\alpha}] \\
+\left(\frac{\partial p}{\partial \ddot{\alpha}}\right) & \frac{d}{d t}[\ddot{\alpha}]
\end{aligned}
$$

which can in turn be written in terms of the moduli defined in eq 2.6 - 2.7:

$$
\frac{d[p]}{d t}=-E_{\mathrm{T}}^{-} \frac{d}{d t}[\alpha]+E_{1}^{-} \frac{d}{d t}[\dot{\alpha}]+E_{2}^{-} \frac{d}{d t}[\ddot{\alpha}] .
$$

Then, substituting eq 7.8 into eq 7.7 gives

$$
\begin{aligned}
& 2 v \dot{V}=\frac{\alpha_{0}}{\rho_{0}} \frac{[p]}{[\alpha]^{2}} \frac{d}{d t}[\alpha]+\frac{\alpha_{0}}{\rho_{0}[\alpha]} E_{\mathrm{T}}^{-} \frac{d}{d t}[\alpha] \\
& -\frac{\alpha_{0} E_{1}^{-}}{\rho_{0}[\alpha]} \frac{d}{d t}[\dot{\alpha}]-\frac{\alpha_{0} E_{2}^{-}}{\rho_{0}[\alpha]} \frac{d}{d t}[\ddot{\alpha}]
\end{aligned}
$$

or

$$
\begin{aligned}
2 V \dot{V} & =\frac{\alpha_{0}}{\rho_{0}[\alpha]}\left(E_{s}^{-}+E_{\mathrm{T}}^{-}\right) \frac{d}{d t}[\alpha] \\
& -\frac{\rho_{0} E_{1}^{-}}{[\alpha] \rho_{0}} \frac{d}{d t}[\dot{\alpha}]-\frac{\alpha_{0} E_{2}^{-}}{\rho_{0}[\alpha]} \frac{d}{d t}[\ddot{\alpha}]
\end{aligned}
$$

where $E_{\mathrm{s}}^{-}$is the secant modulus, $[p] /[\alpha]$.

Calculate now an expression for $[\partial p / \partial X]$ in eq 7.6.

From eq $2.9,[\partial p / \partial X]$ can be expressed as

$$
\begin{gathered}
\frac{1}{\rho_{0}}\left[\frac{\partial p}{\partial X}\right]=-\frac{E_{\mathrm{T}}^{-}}{\rho_{0}}\left[\frac{\partial \alpha}{\partial X}\right]+\frac{E_{1}^{-}}{\rho_{0}}\left[\frac{\partial \dot{\alpha}}{\partial X}\right] \\
+\frac{E_{2}^{-}}{\rho_{0}}\left[\frac{\partial \ddot{\alpha}}{\partial X}\right] .
\end{gathered}
$$

Then eq 7.6 becomes

$$
\begin{gathered}
\frac{2 V}{\alpha_{0}} \frac{d}{d t}[\alpha]+\frac{[\alpha]}{\alpha_{0}} \dot{V}=\left(\frac{-E_{\mathrm{T}}^{-}}{\rho_{0}}+\frac{V^{2}}{\alpha_{0}}\right)\left[\frac{\partial \alpha}{\partial X}\right] \\
+\frac{E_{1}^{-}}{\rho_{0}}\left[\frac{\partial \dot{\alpha}}{\partial X}\right]+\frac{E_{2}^{-}}{\rho_{0}}\left[\frac{\partial \ddot{\alpha}}{\partial X}\right]
\end{gathered}
$$

where $\dot{V}$ is given by eq 7.9 .

The compatibility condition can be used to derive the two equations:

$$
\begin{aligned}
& \frac{E_{1}^{-}}{\rho_{0}}\left[\frac{\partial \dot{\alpha}}{\partial X}\right]=\frac{E_{1}^{-}}{\rho_{0}} \frac{d}{d t}\left[\frac{\partial \alpha}{\partial X}\right]-\frac{E_{1}^{-}}{\rho_{0}} V\left[\frac{\partial^{2} \alpha}{\partial X^{2}}\right] \\
& \frac{E_{2}^{-}}{\rho_{0}}\left[\frac{\partial \ddot{\alpha}}{\partial X}\right]=\frac{E_{2}^{-}}{\rho_{0}} \frac{d}{d t}\left[\frac{\partial \dot{\alpha}}{\partial X}\right]-\frac{E_{2}^{-}}{\rho_{0}} V\left[\frac{\partial^{2} \dot{\alpha}}{\partial X^{2}}\right] .
\end{aligned}
$$

Although not shown, an equation for $\left[\partial^{2} \dot{\alpha} / \partial X^{2}\right]$ can also be developed by using the compatibility conditions presented in Section III.

If we substitute for $\left[\partial^{2} \dot{\alpha} / \partial X^{2}\right]$ and $[\partial \dot{\alpha} / \partial X]$ in eq 7.13 , we can then get:

$$
\begin{gathered}
\frac{E_{2}^{-}}{\rho_{0}}\left[\frac{\partial \ddot{\alpha}}{\partial X}\right]=\frac{E_{2}^{-}}{\rho_{0}} \frac{d}{d t}\left\{\frac{d}{d t}\left[\frac{\partial \alpha}{\partial X}\right]-V\left[\frac{\partial^{2} \alpha}{\partial X^{2}}\right]\right\} \\
-\frac{E_{2}^{-}}{\rho_{0}} V\left\{\frac{d}{d t}\left[\frac{\partial^{2} \alpha}{\partial X^{2}}\right]-V\left[\frac{\partial^{3} \alpha}{\partial X^{3}}\right]\right\} .
\end{gathered}
$$

Equation 7.11 then becomes, after substituting for $[\partial \dot{\alpha} / \partial X]$ and $[\partial \ddot{\alpha} / \partial X]$,

$$
\frac{2 V}{\rho_{0}} \frac{d}{d t}[\alpha]+\left\{\frac{[\alpha]}{\alpha_{0}}+\frac{E_{2}^{-}}{\rho_{0}}\left[\frac{\partial^{2} \alpha}{\partial X^{2}}\right]\right\} \dot{V}
$$




$$
\begin{gathered}
=\left(\frac{E_{\mathrm{T}}^{-}}{\rho_{0}}+\frac{V^{2}}{\alpha_{0}}\right)\left[\frac{\partial \alpha}{\partial X}\right]+\frac{E_{1}}{\rho_{0}} \frac{d}{d t}\left[\frac{\partial \alpha}{\partial X}\right] \\
+\frac{E_{2}^{-}}{\rho_{0}} \frac{d^{2}}{d t^{2}}\left[\frac{\partial \alpha}{\partial X}\right]-\frac{E_{1}^{-} V}{\rho_{0}}\left[\frac{\partial^{2} \alpha}{\partial X^{2}}\right] \\
-\frac{E_{2}^{-} V}{\rho_{0}} \frac{d}{d t}\left[\frac{\partial^{2} \alpha}{\partial X^{2}}\right]+\frac{E_{2}^{-} V^{2}}{\rho_{0}}\left[\frac{\partial^{3} \alpha}{\partial X^{3}}\right] .
\end{gathered}
$$

Equation 7.9 can be substituted into eq 7.15 to eliminate $\dot{V} ;$ and this results in an equation which contains the terms $d[\dot{\alpha}] / d t$ and $d[\ddot{\alpha}] / d t$. Again, the compatibility equations can be used to eliminate these terms. For the sake of brevity, this will not be done here. Eventually we can arrive at an equation of the following form:

$$
\begin{array}{r}
\frac{d}{d t}[\alpha]=A_{1}\left[\frac{\partial \alpha}{\partial X}\right]+A_{2} \frac{d}{d t}\left[\frac{\partial \alpha}{\partial X}\right]+A_{3} \frac{d^{2}}{d t^{2}}\left[\frac{\partial \alpha}{\partial X}\right] \\
+B_{1}\left[\frac{\partial^{2} \alpha}{\partial X^{2}}\right]+B_{2} \frac{d}{d t}\left[\frac{\partial^{2} \alpha}{\partial X^{2}}\right]+C_{1}\left[\frac{\partial^{3} \alpha}{\partial X^{3}}\right]
\end{array}
$$

where $A_{1}, B_{1}$, and $C_{1}$ are all functions of $[\alpha], E_{\mathrm{T}}^{-}, E_{1}^{-}$, $E_{2}^{-}$, and $V$. The above holds for any shock wave propagating in a material for which the constitutive law has $p$ as a function of $\alpha, \dot{\alpha}$ and $\ddot{\alpha}$.

In the present form, eq 7.16 is quite complicated and therefore not very amenable to solution. We now consider some approximations, which put the formulation in a simpler form.

\section{REDUCED JUMP EQUATIONS}

We consider now a simplified form of the jump equation given by eq 7.15 . We first define the wavelength to be such that higher order derivatives in $\alpha$ become negligible behind the wave. This means that behind the wave front, the following conditions hold:

$$
\begin{aligned}
& \frac{d}{d t}[\alpha],\left[\frac{\partial \alpha}{\alpha X}\right] \neq 0 \\
& {\left[\frac{\partial^{2} \alpha}{\alpha X^{2}}\right], \frac{d^{2}}{d t^{2}}[\alpha], \text { etc. }=0 .}
\end{aligned}
$$

In this way, we study the conditions behind the wave where the motion has stabilized so that higher order derivatives are no longer significant. This assumption then simplifies the mathematics and greatly facilitates the solution of the problem. This type of wave we refer to as a semi-steady wave. This type of wave should give a better approximation than assuming the wave to be steady.

Equation 7.15 reduces to the following form:

$$
\frac{2 V}{\rho_{0}} \frac{d}{d t}[\alpha]=-\frac{[\alpha]}{\alpha_{0}} \dot{V}+\left(\frac{E_{\mathrm{T}}^{-}}{\rho_{0}}+\frac{V^{2}}{\alpha_{0}}\right)\left[\frac{\partial \alpha}{\partial X}\right] .
$$

From eq 7.7, we can get

$$
\dot{V}=\frac{\alpha_{0}}{2 V \rho_{0}[\alpha]}\left(E_{\mathrm{s}}^{-}-E_{\mathrm{t}}^{-}\right) \frac{d}{d t}[\alpha]
$$

Then eq 8.2 becomes

$$
\left(\frac{2 V}{\rho_{0}}+\frac{E_{\mathrm{s}}^{-}-E_{\mathrm{T}}^{-}}{2 \rho_{0} V}\right) \frac{d}{d t}[\alpha]=\left(\frac{E_{\mathrm{T}}^{-}}{\rho_{0}}+\frac{V^{2}}{\alpha_{0}}\right)\left[\frac{\partial \alpha}{\partial X}\right] .
$$

Equation 8.4 could be solved rather than eq 6.2. This latter formulation would give a computationally much more efficient solution, but some information would be lost. For instance, no knowledge of the stress wave profile as shown in Figures 6 and 7 can be obtained by solution of eq 8.6. This equation is primarily useful for evaluation of stress wave attenuation in terms of the variable $[\alpha]$.

\section{DISCUSSION AND CONCLUSIONS}

The foregoing sections have considered the problem of a plane pressure wave propagating through unstressed medium-to-high density snow. By first assuming the pressure wave to be steady, some information concerning the properties of plastic stress waves can be obtained. By not assuming the wave to be steady, a fairly precise determination of pressure wave attenuation and profile change can be made.

For steady waves, a measure of pressure jump, density change and wave speed can be readily found at a point in the medium. Also, a measure of the pressure profile within the wave can be made. As was demonstrated, the wave speed varies strongly with the wave intensity. Plastic waves are generally considerably slower than elastic waves; and for the most part, wave speed tends to increase with wave intensity for pressures above 10 bar.

A good deal more information can be obtained by not assuming the stress wave to be steady and solving the equations of motion and mass conservation directly. 
Such a solution was done by the finite difference method, since the field equations were nonlinear.

Wisotski and Snyder (1966) observed, as did Gubler (1977), that charges detonated over the snowpack produced much larger pressures within the snowpack than did a charge placed in the pack. Apparently much of the charge energy is dissipated in the snowpack by melting and vaporization in the immediate charge neighborhood. Such thermodynamic processes have tremendous potential for absorbing energy. This would not occur for an airdetonated charge. An additional reason for the relative effectiveness of air-detonated charges is the significant difference in the wave-attenuating capabilities of air and snow. A pressure wave propagating several meters in snow would go through several orders of magnitude more attenuation in snow than in air, since air reacts elastically to pressure waves.

The superiority of air-detonated explosions could be put to good use for initiating avalanches. The presentday practice consists of placing the charge in the snowpack, which apparently is a very inefficient method. Quite possibly a smaller, more economical, version of the Army's SLUFAE system could be developed for avalanche control. Now that the $105-\mathrm{mm}$ recoilless rifle is being replaced by howitzers in many ski areas, such a system might be adapted to the howitzers. Economics, however, might be a limiting factor.

The results of this study also indicate that the effectiveness of the SLUFAE system for clearing snow covered mine fields may be severely impaired by a shallow snowpack. A 6-in. snowpack could attenuate most of the 21-bar pressure generated by the air blast of the SLUFAE ballistic. Figure 9 shows that within 3 in. the pressure is reduced to about $2 \mathrm{bar}$, and another 3 in. of snowpack would attenuate this even further.

Figure 9 also indicates that increasing the overburden pressure from 6 bar to 21 bar does not produce a corresponding increase in effectiveness. By 3 in. into the snowpack, most of the pressure advantage of the 21 bar surface pressure is lost. This result may indicate that a smaller system generating a lower overburden pressure will work as well for either initiating avalanches or clearing snow-covered mine fields.

In plastic waves, frequency apparently does not play a dominant factor in determining wave attenuation rates. This is not so for elastic waves, where high frequency waves tend to dissipate more rapidly than lower frequency waves. The word elastic is a misnomer here, since some sort of internal dissipation mechanism must be responsible for the difference in attenuation rates. These low intensity waves are elastic in the sense that no apparent plastic deformation is associated with these waves.

\section{LITERATURE CITED}

Abele, G. and A. Gow (1975) Compressibility characteristics of compacted snow. U.S. Army Cold Regions Research and Engineering Laboratory, CRREL Report 76-21. AD A028622.

Ames, W.F. (1965) Nonlinear partial differential equations. New York: Academic Press.

Brown, R.L. (1978a) High rate volumetric characteristics of snow. Journal of the Mechanics Division, ASCE (submitted for publication).

Brown, R.L. (1978b) Pressure waves in snow. Journal of Glaciology (in press).

Coleman, B.D., M.E. Gurtin and I. Herrera (1964) Waves in materials with memory. Archives of Rational Mechanics and Analysis, vol. 19, p. 1-19.

Gubler, H. (1977) Artificial release of avalanches by explosives. Journal of Glaciology, vol. 19, no. 81, p. 419-429.

Johnson, J.B. (1978) Stress waves in snow. Department of Geophysics, University of Washington, Ph. D. Thesis.

Mellor, M. (1977) The engineering properties of snow. Journal of Glaciology, vol. 19, no. 81, p. 15-66.

Napadensky, H. (1964) Dynamic response of snow to high rates of loading. CRREL Research Report 119. AD 600075 .

Nunziato, J.W. and E.K. Walsh (1978) One dimensional shock waves in uniformly distributed granular materials. International Journal of Solids and Structures, vol. 14, p. 681-689.

Wakahama, G. and A. Sato (1977) Propagation of a plastic wave in snow. Journal of Glaciology, vol. 19, no. 81, p. $175-184$.

Wisotski, J. and W. Snyder (1966) A study of the effects of snow cover on high explosive blast parameters. University of Denver, Denver Research Institute Report no. 2303. 
A facsimile catalog card in Library of Congress MARC format is reproduced below.

Brown, Robert L.

An analysis of plastic shock waves in snow / by Robert L. Brown. Hanover, N.H.: U.S. Cold Regions Research and Engineering Laboratory; Springfield, Va.: available from National Technical Information Service, 1979.

v, 19 p., illus.; 27 cm. ( CRREL Report 79-29.)

Prepared for Directorate of Military Programs - Office, Chief of Engineers by Corps of Engineers, U.S. Army Cold Regions Research and Engineering Laboratory under DA Project 4A161102AT24.

Bibliography: p. 14 .

1. Plastic shock waves. 2. Shock waves. 3. Snow. 4. Snow loads. I. United States. Army Corps of Engineers. II. Army Cold Regions Research and Engineering Laboratory, Hanover, N.H. III. Series: CRREL Report 79-29.

מU.S. GOVERNMENT PRINTING OFFICE: $1979=602-519 / 322$ 